\title{
La alimentación del Ejército de Tierra en operaciones. La ración individual de combate
}

\author{
Arcarazo García LA. ${ }^{1}$
}

Sanid. mil. 2014; 70 (4): 293-306; ISSN: 1887-8571

\begin{abstract}
RESUMEN
La alimentación de los ejércitos ha sido tradicionalmente un problema bastante complejo, que ha estado en función de dos aspectos fundamentales, la capacidad económica del que lo financiaba, reyes, haciendas o estados, y la posibilidad de conseguir alimentos. Por otra parte, el valor alimenticio de aquellos "ranchos militares" dejaba mucho que desear, frecuentemente por falta de principios inmediatos y por carencias vitamínicas, ya que se trataba de raciones con muy poca carne y carentes de productos frescos, lo que daba lugar a enfermedades carenciales y a la falta de condiciones físicas entre los militares. De todas formas, la preocupación por una adecuada alimentación de los ejércitos también viene de lejos, habiendo dado lugar a la publicación de infinidad de libros y normas, hasta llegar a los verdaderos tratados de alimentación con carácter científico publicados a partir de finales del siglo XIX. El soldado del Ejército español ha padecido carencias alimentarias tanto en las colonias como en la península, debido siempre a la precariedad de recursos. Su alimentación fue mejorando cuando el país remontó las privaciones derivadas de la Guerra Civil a partir de los años sesenta del siglo pasado, siendo una verdadera novedad la introducción de las "raciones de previsión" en los años noventa, que no solo facilitó la alimentación en ejercicios y maniobras en territorio nacional sino la de los contingentes destacados en las diferentes misiones en el extranjero.
\end{abstract}

PALABRAS CLAVE: alimentación, ración de campaña, ración de previsión, alimentación colectiva, ración individual de combate, ración colectiva.

\section{Ground Forces nutrition in operations. Individual ration in combat}

SUMMARY: the nutrition of the armies has traditionally been a fairly complex problem that has been based on two fundamental aspects, the economic capacity of those who were financing it (kings, the Inland Revenues or states), and the possibility of obtaining food. On the other hand, the nutritional value of those "military single-course meals" was leaving much to be desired, usually for the lack of immediate principles and vitamin deficiencies as the portions had very little meat and were lacking fresh products, what gave rise to deficiency diseases and the lack of physical condition among soldiers. Anyway, the concern for a proper nutrition of the armies reaches far back into the past, having led to the publication of countless books and standards all the way up to the real treaties of scientific character, published since the beginning of the 19th century. Soldiers of the Spanish army have suffered from food shortages both in the colonies and in the peninsula, always due to the resources instability. Their nutrition was improved when the country mended the losses arising from the Civil war in the decade of 1960, being a real novelty the introduction of "forecast rations" in the 1990s, which not only provided food in exercises and maneuvers in national territory, but also for the troops stationed in the different missions abroad.

KEY WORDS: nutrition, campaign ration, forecast ration, collective nutrition, individual combat ration, collective ration.

\section{INTRODUCCIÓN}

Uno de los principales problemas logísticos al que se han enfrentado los ejércitos de todos los tiempos ha sido su manutención, agravado cuando entraban en campaña, ya que a la precariedad habitual de medios se sumaba la falta de recursos de los territorios devastados por los combates, mientras que en las guerras modernas el problema se ha visto incrementado por el alargamiento de las líneas de aprovisionamiento, como puede ser el caso de Afganistán.

${ }^{1}$ Cor. Médico. Academia General Militar. Zaragoza. España.

Dirección para correspondencia: larcaraz@et.mde.es

Recibido: 25 de octubre de 2013

Aceptado: 19 de febrero de 2014

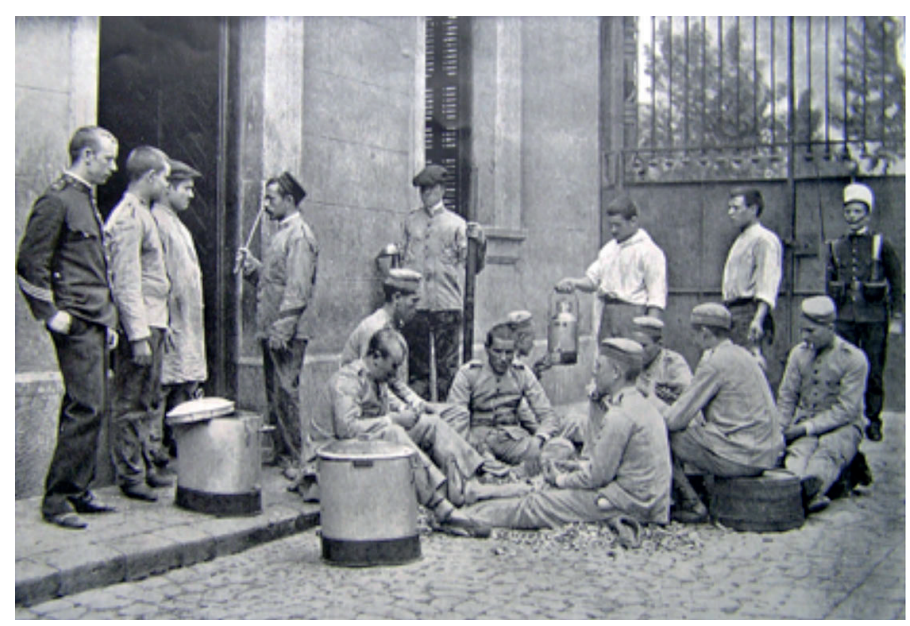

Figura 1. Soldados pelando patatas. (El Ejército español. Colección de fotografías instantáneas). 


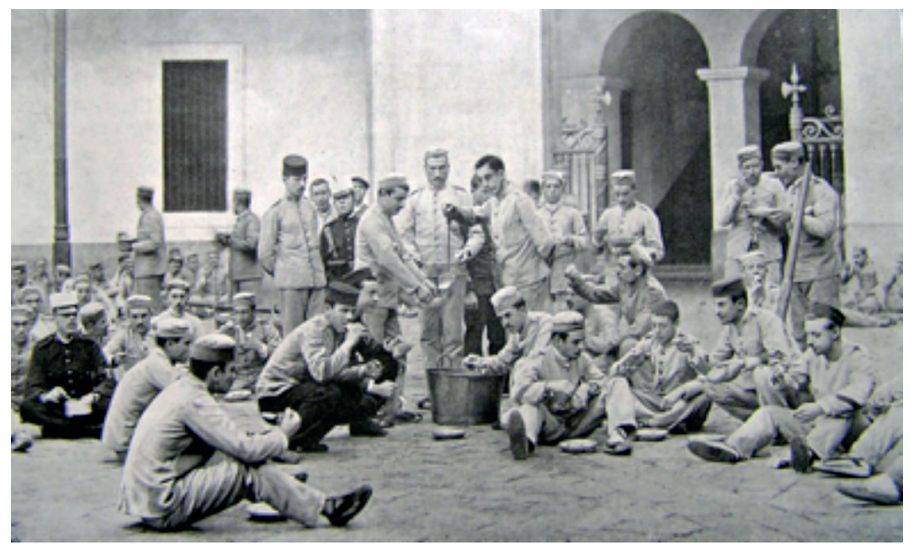

Figura 2. Soldados comiendo en el patio del cuartel. (El Ejército español. Colección de fotografías instantáneas).

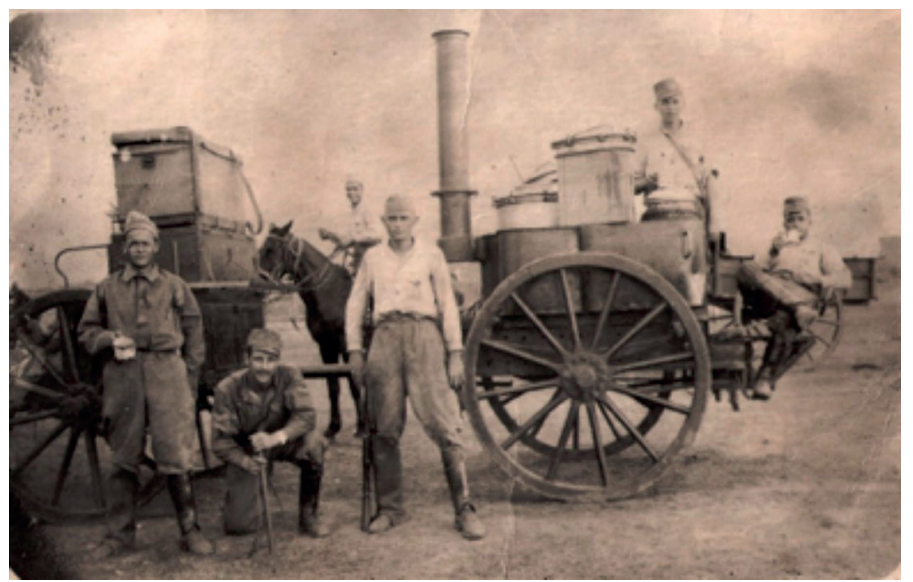

Figura 3. Cocina de campaña alemana en 1914.

Para intentar paliar los problemas alimenticios de los soldados, se han publicado infinidad de normas, reglamentos y libros, de los cuales habría que destacar el escrito por Mr. Pringle en 1775, que tuvo bastante difusión en España. Este libro tiene la particularidad de hacer un estudio higiénico-sanitario de los ejércitos del momento y en lo concerniente a la alimentación de la tropa refiere, que había que obligar a los soldados a comer el rancho para que estuvieran bien alimentados, ya que si se les daba la soldada en mano, se la gastaban no precisamente en alimentarse. En lo relativo al suministro de alimentos, apuntaba la importancia que tenía el conseguir legumbres, ya que, de lo contrario, los soldados se alimentaban mal con frutas verdes y carne de cerdo, por lo que hacía responsables a los oficiales de que sus soldados comieran correctamente en campaña. También consideraba mejor el bizcocho que el pan, pues "éste suele estar mal cocinado, precisa mucho trabajo y gente y, además, le añadían "mil cosas". Entre las carnes era preferible la de ternera, simplemente porque estos animales seguían mejor al ejército y podían pastar ${ }^{1}$.

Por otra parte, achacaba a la mala alimentación de los soldados una serie de enfermedades, como el escorbuto, la disentería o las calenturas pútridas, por lo que recomendaba darles diariamente sopa y cocido para la comida, asado en la cena y $1^{\prime} 5$ libras de pan de munición, que se debería de confeccionar con una mezcla de $2 / 3$ de harina de trigo y $1 / 3$ de harina de centeno. En caso de fallar la carne o el pan, se deberían de sustituir por vegetales, como la "acedera", rábanos, espinacas, nabos, zanahoria, cebolla, teniendo mucha precaución con los frutos verdes, pues producían disentería. Mr. Pringle refiere, que el agua debía de ser abundante, proceder de ríos o arroyos próximos a los campamentos, pero antes de consumirla era preciso filtrarla por arena y darle aroma con vino, aguardiente o vinagre, ya que este último "disipa los humores espesos, es antiinflamatorio y actúa como antiputrefacción". Este libro tuvo mucha difusión entre médicos y cirujanos durante las guerras napoleónicas.

A comienzos del siglo XIX hay constancia de que la ración diaria del soldado francés en la Guerra de España era de 24 onzas de pan ordinario ó 18 de bizcocho, 8 de carne fresca o salada, 6 de tocino salado, 1 de arroz, 2 de legumbres, $1 / 2$ ó 1/4 de pinta de vino para cuatro y 1 libra de sal para 30 soldados $^{2}$, por otra parte, en su mochila debía de llevar la provisión de carne para dos días, que se podría considerar como una ración individual de campaña ${ }^{3}$ Y para hacerse una idea aproximada de cuál era la alimentación del soldado español, puede servir la reglamentaria en los hospitales militares de campaña en 1811, cuya dieta consideraba como alimentos y condimentos de uso ordinario el pan, las carnes de carnero, vaca o ternera, el arroz, el chocolate, el vino común, la sidra o la cerveza y como condimentos la sal y el aceite, mientras que entre los alimentos extraordinarios estaban la manteca, manos, lengua, criadillas y sus menudillos, leche, verdura, fruta, vino generoso, vinagre, mostaza y pimienta ${ }^{4}$.

\section{LA ALIMENTACIÓN DEL SOLDADO ESPAÑOL}

De todos los historiadores que han trabajado sobre el ejército español sólo unos pocos han investigado sobre su alimentación, como René Quatrefages. Refiere que la alimentación del soldado de los tercios españoles consistía en $3 / 4$ de $\mathrm{Kg}$. de pan o bizcocho, una libra de carne, media de pescado y medio litro de vino, aderezado con aceite y vinagre, lo que le aportaba entre 3.300 y 3.900 calorías/día. La alimentación corría a cargo de los propios soldados, con su paga de 3 escudos al mes, debiendo cocinar ellos mismos, aunque la preparación de algunos alimentos corría a cargo de cada uno de los camaradas en los fogones del campamento 5 .

Por su parte, Fernando Fernández Bastarreche, en sus estudios sobre el Servicio Militar en España en el siglo XIX, refiere que la alimentación de los soldados era deficiente de forma habitual, ya que las calorías de los diferentes ranchos estudiados, en el mejor de los casos, tendrían entre 2.800 y 2.900 calorías. El rancho tipo se componía de 250 gr. de patatas, 88 gr. de garbanzos, 25 gr. de arroz, 50 gr. de habichuelas, 25 gr. de tocino y 31 gr. de carne, con sus condimentos, lo que suponía 2.142 calorías, totalmente insuficientes para un mozo en filas. Del estudio de la composición de los ranchos se deduce, que "aparte la insuficiencia calórica, la defectuosa calidad en productos nutritivos, al carecer todos los ranchos, casi sin excepción, de proteínas de origen animal. Las frutas, verduras frescas, huevos, productos lácteos y casi por completo la carne y el pescado, están ausentes en casi todos estos modelos". La alimentación del soldado español 
era de las peores, comparándola con la de otros ejércitos europeos, ya que frente a los 200 gr. de carne del ejército italiano o los 340 gr. del inglés, el soldado español sólo recibía 31 gr., aunque también es cierto, que esta alimentación no era peor que la que consumía en su casa, carente casi de carne, huevos o pescado sobre todo en regiones del interior, ya que el pan era la base de la alimentación de las clases medias y bajas españolas, que eran precisamente las que nutrían las filas del ejército ${ }^{6}$.

La alimentación del soldado podía mejorar algo cuando estaba hospitalizado, por ejemplo, en el Hospital de San Julián y Sta. Lucía de Barbastro la dieta del soldado en 1839 consistía en 10 onzas de carne y 1 onza de garbanzos, con lo que se confeccionaba un cocido, además le daban 1'5 libras de pan y un cuartillo de vino, ración bastante mejor que la del resto de pacientes civiles ${ }^{7}$. Pero durante las guerras carlistas el suministro de alimentos fue casi imposible. Las tropas isabelinas en la primera guerra pasaron constantes privaciones, ya que raramente se les podía dar carne, precisamente cuando la situación más lo requería, y sólo multando y amenazando a los vecinos de los pueblos se conseguía vino para los soldados, que era una forma de aumentar las calorías, aunque sin las necesarias proteínas animales. Las raciones de etapa también eran de mala calidad y de poca cantidad, "En ocasiones, divisiones enteras se quedaban días enteros sin pan.../...por lo que el estado sanitario del ejército dejaba mucho que desear, y los hospitales se encontraban atestados de enfermos".

De todas formas, la preocupación por la alimentación del soldado fue constante y un buen ejemplo es el libro titulado Notas a la vista. Tratado teórico-práctico de los productos alimenticios que son objeto del comercio y de que hace uso el Ejército en paz y en campaña, escrito en 1894 por el comisario de guerra de $2^{\mathrm{a}}$ clase Rafael Quevedo y Medina, que hace un estudio pormenorizado de los cereales, legumbres, harina, pan, azúcar, té, chocolate, bebidas alcohólicas, agua potable, quesos, bacalao, pastas para sopa, galleta y raciones de etapa. También

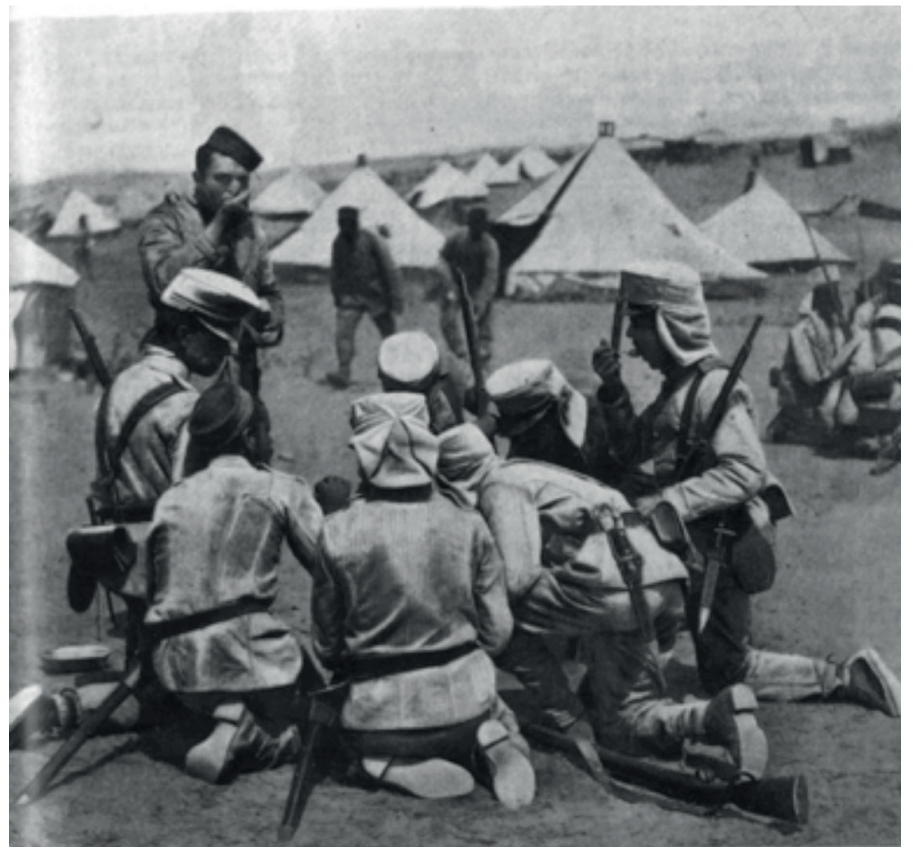

Figura 4. Soldados españoles comiendo. Marruecos 1912.

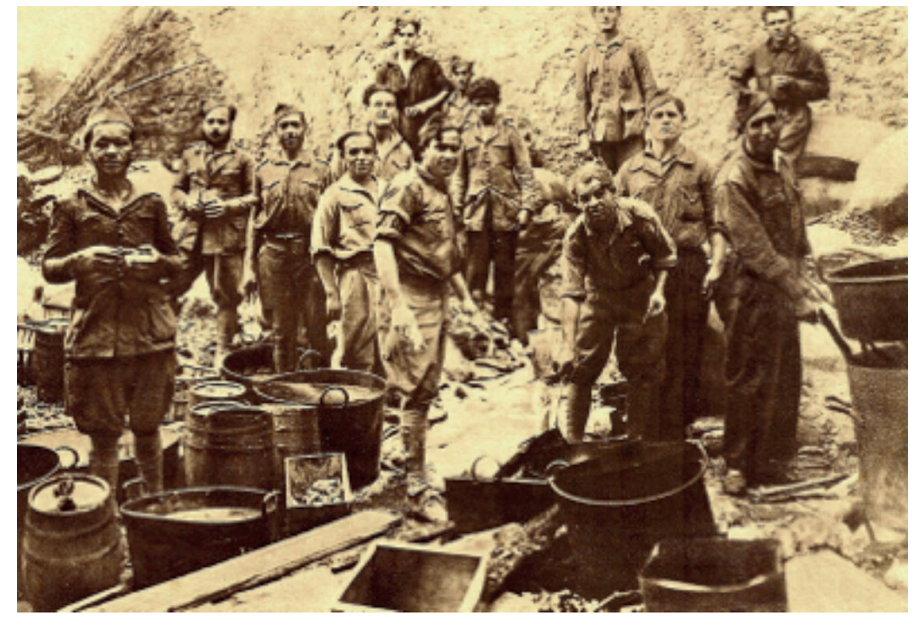

Figura 5. Legionarios cocinando durante la guerra civil.

repasa lo relativo al ganado bovino, vacuno, cabras, suinos o cerdos y équidos. Y para concluir, incluye las diferentes medidas y pesas de varios países y los valores de las principales monedas europeas ${ }^{9}$.

Se trata de una obra científica según la cual para sostener la vida y las fuerzas era imprescindible que los alimentos que constituían la ración de un hombre, deberían de contener 310 gr. de carbono y 130 de sustancias azoadas, para lo cual incluía una tabla con la cantidad de ázoe, carbono, grasa y agua que contienen productos como la carne sin hueso de los rumiantes, bacalao, arenques salados, quesos, frutos y legumbres, aclarando que los elementos nutritivos azoados se denominan: albuminatos, elementos albuminoideos, elementos proteicos o simplemente proteínas, ya que su carácter esencial era contener de 0’15 a 0'16 de ázoe "Tales son: la albúmina vegetal, la legumina, el gluten, la albúmina y fibrina animales etc." También describe la galleta como un pan plano y seco, que no debe de atraer la humedad atmosférica, ser quebradizo y de corteza poco espesa, que tiene la ventaja de conservarse largo tiempo y reunir con menor volumen la misma cantidad de materias nutritivas. La pasta de la galleta se preparaba con amasaderas del sistema Deliry y luego se pasaba por aparatos del sistema Bernadou, que mediante unos rodillos laminaban la masa, unas cuchillas y punzones la taladraban y cortaban en porciones de 200 gr. La galleta debía permanecer 15 días secándose antes de poder ser consumida ${ }^{10}$.

Para las raciones de etapa de los soldados, el mencionado libro propone nueve menús diferentes, especificando los ingredientes de las dos comidas diarias, por ejemplo, en la $2^{\mathrm{a}}$ ración de etapa la comida se componía de 250 gr. de carne y 200 de arroz, mientras que en la cena serían 250 gr. de carne con 200 de garbanzos. La comida de la $3^{\text {a }}$ ración de etapa tendría 250 gr. de carne y 200 gr. de judías, mientras que en la cena habría 250 gr. de carne con 300 gr. de habas. Había varias raciones con bacalao, como la comida de la $4^{\text {a }}$ ración, que se componía de 250 gr. del mencionado pescado, 100 gr. de arroz y 50 gr. de aceite, mientras que en la cena serían 250 gr. de bacalao, 200 gr. de judías y 50 gr. de aceite. En la $7^{\mathrm{a}}$ ración había 100 gr. de tocino con 250 gr. de habas y en la cena 100 gr. de tocino con 200 gr. de arroz y, por último, en la $9^{a}$ ración la comida tendría 250 gr. de carne, 50 gr. de tocino y 500 gr. de patatas. En todas ellas se expresan los gramos de ázoe y de carbono que contenían. El autor incluye como 


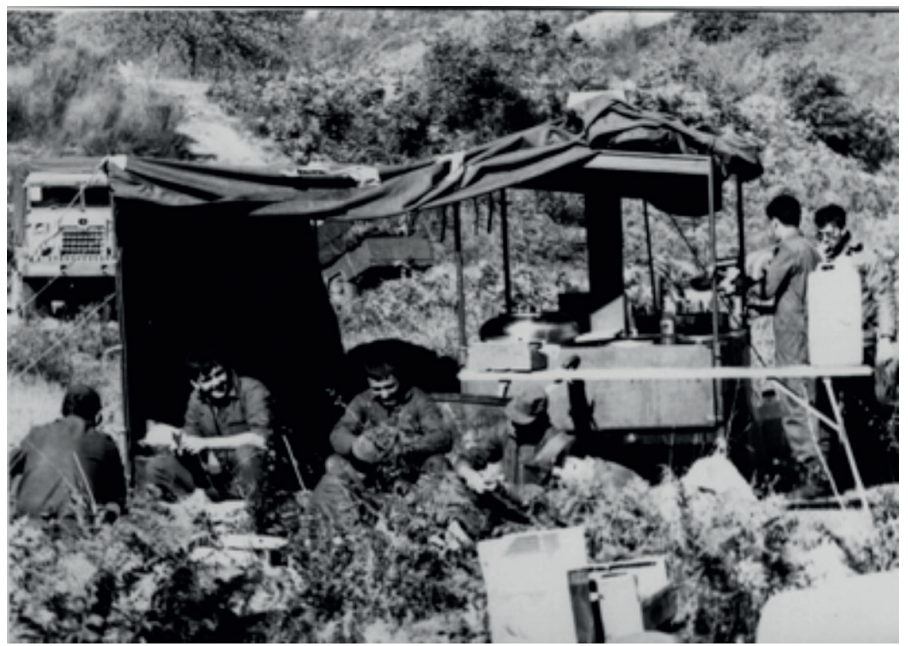

Figura 6. Cocina ARPA. Foto del autor, 1983.

ejemplo las tres raciones extraordinarias que utilizó el Ejército del Norte en diciembre de 1874, una con judías, bacalao, arroz y aceite, de 920 gr. Otra con judías, bacalao, garbanzos y aceite, también con 920 gr. y la última con chorizo y tocino, con un total de 200 gr., además menciona raciones especiales, como la de café con azúcar, la de vino de $50 \mathrm{ml}$. y la de aguardiente con la misma cantidad. La ración de convite o recompensa se componía de galleta, pan, queso manchego y aguardiente, mientras que la de refresco, para días de calor excesivo, se compondría de galleta, pan, ajos, sal, vinagre y aceite ${ }^{11}$.

El libro estaba dedicado especialmente a los oficiales del Cuerpo de Administración Militar, pues consideraba que "La Administración Militar es el elemento más fecundo del orden y disciplina de un Ejército. Las operaciones de un Ejército deben subordinarse siempre a la posibilidad administrativa. Nada es en un Ejército el hierro y el fuego enemigo, comparado con la falta de asistencia" ${ }^{12}$. Es decir, que a finales del siglo XIX ya había autores que tenían muy claro, que sin la logística oportuna nada podía un ejército, por muy bien armado y entrenado que estuviera $^{13}$.

De una forma general se puede decir, que durante el siglo XIX y a comienzos del XX la alimentación reglamentaria de los soldados de guarnición, campaña o, incluso, en los hospitales,

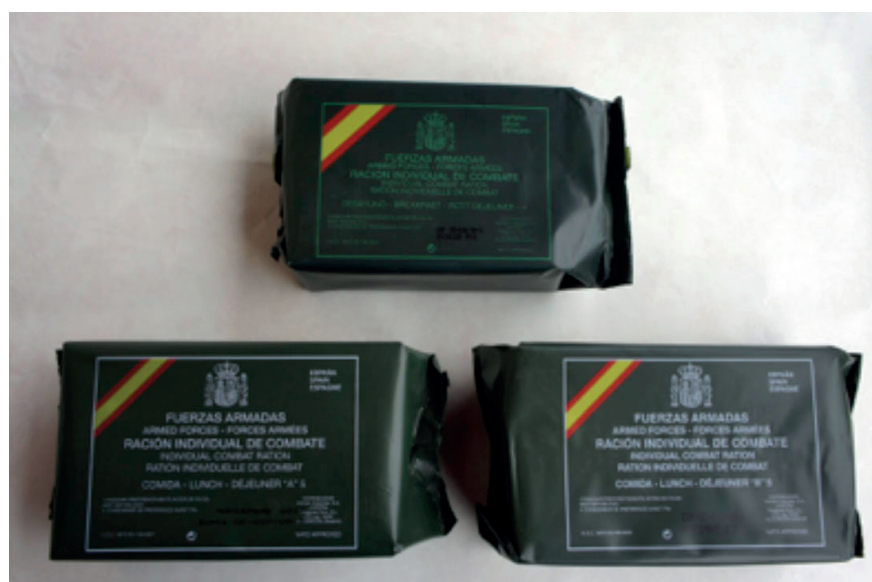

Figura 7. Paquetes de desayuno, comida y cena. Foto del autor. consistía en un guiso confeccionado con legumbres, carne y tocino salado, condimentado con sal y aceite, acompañado de pan o pan galleta y vino. El cocido o rancho se hacía una vez al día y se repartía entre la comida y la cena.

\section{PRIMEROS PASOS DE LAS RACIONES DE CAMPAÑA}

Cuando realmente los ejércitos comenzaron a experimentar con raciones individuales específicas de campaña fue en las dos guerras mundiales, generalizándose el uso de raciones que no precisaban más que calentarlas. En la $1^{\circ}$ Guerra Mundial la alimentación de los soldados fue en ambos bandos muy deficiente. En la fase de guerra de movimientos la comida se preparaba en cocinas rodantes de campaña, pero cuando se pasó a la guerra de trincheras, la comida tuvo que confeccionarse en la retaguardia, dando lugar a que le llegara fría al soldado o que ni siquiera llegara a primera línea, por lo que hubo que diseñar una serie de raciones, que deberían de tener 4.000 Kilocalorías diarias, aunque con deficiencias vitamínicas, debido a la falta de verduras y fruta fresca ${ }^{14}$.

Aunque las latas de conserva ya las utilizó el Ejército del Emperador Napoleón, fue en la $1^{\text {a }}$ Guerra Mundial cuando se diseñaron raciones de trinchera, especialmente para las tropas de primera línea, siempre difíciles de aprovisionar. Consistían en carne enlatada, pan y café, pudiendo ser consumidas en frío

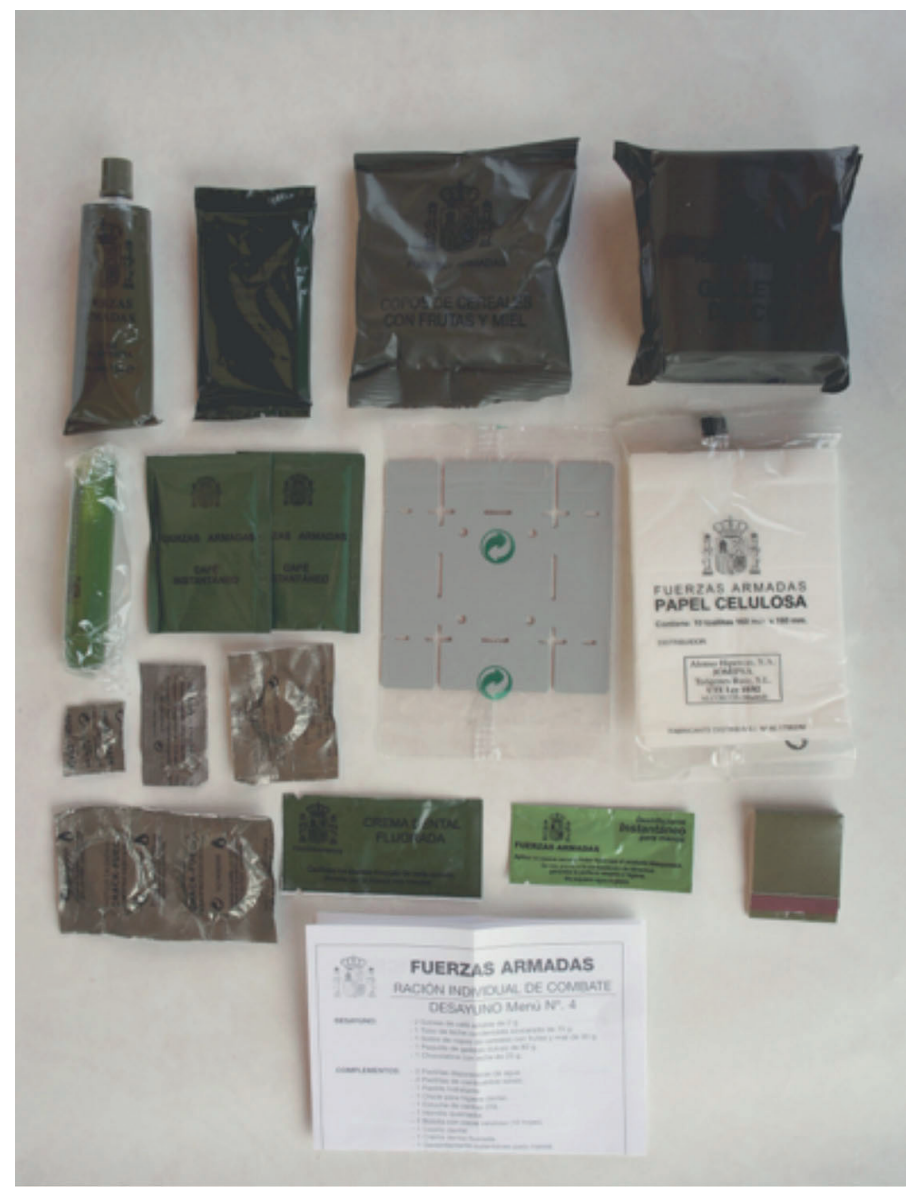

Figura 8. Contenido de un desayuno con sus complementos. Foto del autor 
o en caliente, ya que incluían pastillas de alcohol solidificado, pero con el inconveniente del peso. También se diseñaron raciones de emergencia enlatadas, que contenían una mezcla de carne en polvo desecada con harina de trigo en forma de galleta y tres tabletas de chocolate. La ración del ejército inglés era la Tommy Cookers, que dio lugar a que a los soldados se les conociera como Tommy's. Pero las raciones colectivas para 14 personas no comenzaron a utilizarse hasta la $2^{\text {a }}$ Guerra Mundial ${ }^{15}$.

\section{Raciones colectivas en el Ejército español}

El Ejército español alimentó a sus soldados durante las guerras de África de forma convencional, aunque en las posiciones más alejadas, de difícil suministro, se utilizaron latas de conserva, sobre todo las de sardinas en aceite, nada recomendables dada la habitual escasez de agua potable. Y, posteriormente, en la Guerra Civil 1936-1939 no hubo cambios importantes, utilizándose la ración en frío para unidades en movimiento.

Posteriormente, comenzaron a utilizarse diferentes cocinas de campaña, como las cañoneras, que funcionaban con leña o carbón y, posteriormente, las cocinas ARPA, que podían usar leña o gas butano indistintamente. También hubo varios in-

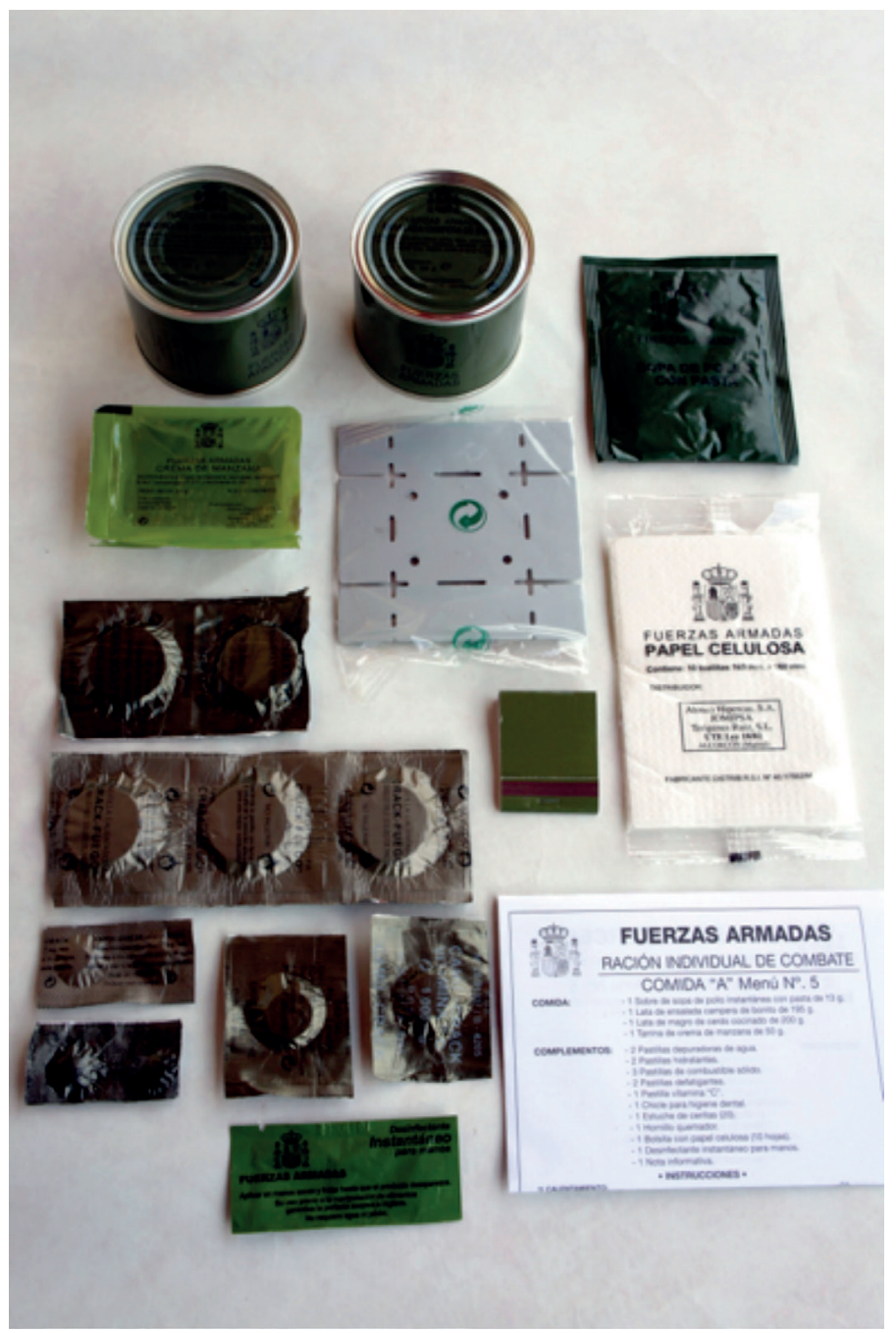

Figura 9. Contenido de una comida. Foto del autor. tentos para disponer de raciones propias, pero sin continuidad, hasta que a comienzos de los años noventa del siglo pasado se diseñaron las primeras raciones colectivas y las individuales. El Centro Técnico de Intendencia realizó una serie de estudios y proyectos, como la "Ración Colectiva de Campaña C9 Experimental" para 9 hombres, antecesora de la de 12 plazas, cuyos estudios datan del año 1990, contemplando latas de conserva de $3 \mathrm{Kg}$. con tres menús diferentes:

- $1^{a}$ comida: garbanzos con bacalao y estofado de ternera. $2^{\mathrm{a}}$ comida: arroz con magro y albóndigas de bonito.

- $1^{a}$ comida: fabada asturiana y pollo con guarnición. $2^{a}$ comida: menestra de verduras y atún con tomate.

$1^{\mathrm{a}}$ comida: canelones y magro con guarnición.

$2^{\mathrm{a}}$ comida: ensalada de atún y salchichas Frankfurt con salsa de tomate.

Posteriormente, en 1991 se diseñó una "Ración Colectiva de Campaña de 36 plazas", prevista para ser una comida completa en campaña, debiendo de cubrir las necesidades de un día. La ración se componía de tres paquetes: desayuno, primera y segunda comidas, además de los suplementos para su reparto y consumo. Se confeccionaron tres menús diferentes con una caducidad de 18 meses para el desayuno y de 3 años para las comidas, siendo su rotulación en español, inglés y francés, como establecía la normativa OTAN. Por ejemplo, la primera comida del menú $n^{\circ} 1$ consistía en cuatro latas de $3 \mathrm{Kg}$. de garbanzos con bacalao, dos latas de $3 \mathrm{Kg}$. de estofado de ternera, dos latas de $3 \mathrm{Kg}$. de melocotón en almíbar y 36 paquetes de 100 gr. de pan galleta.

Dos años después se diseñó la "Ración Colectiva de Campaña de 12 plazas" con las mismas características que su antecesora y en 1995 se adaptó la "Ración Colectiva de Campaña de 10 plazas", con latas de $3 \mathrm{Kg}$., introduciendo algún plato nuevo como: albóndigas de atún, carne de vacuno con guisantes, raviolis con carne y champiñones o salchichas con salsa de tomate. También se componían de desayuno, comida, cena y postres. Por su parte, el pan galleta se contrataba y distribuía aparte, mientras que los complementos quedaban a criterio de la Unidad a la que pertenecían los usuarios de la ración. Junto a estas raciones colectivas se comenzó a fabricar la "Ración Individual de Campaña" y la "Ración de Emergencia", con módulos para desayuno, comida y cena, con los complementos necesarios para calentar y condimentar los alimentos. Las raciones colectivas fueron cayendo en desuso, consolidándose las individuales.

Recientemente, tras casi veinte años sin fabricar raciones colectivas, se ha vuelto a pensar en su idoneidad, debido a que la misión en Afganistán tiene ciertas particularidades frente a las anteriores, ya que precisa de un despliegue en pequeños destacamentos, que pueden pasar periodos relativamente prolongados de aislamiento. Todo lo cual dio lugar al diseño de una nueva "Ración Colectiva de Campaña de 10 plazas", compuesta de dos latas de $3 \mathrm{Kg}$. con primero y segundo plato, no haciéndose distinción entre comida y cena. Del diseño se encargó el Parque y Centro de Abastecimiento de Material de Intendencia (PCAMI) y, en concreto, la Unidad de Estudios, Proyectos y Laboratorio, que creó una ración con 10 menús y un total de 19 platos diferentes, incluyendo pan galleta y complementos. Esta ración ha tenido muy buena aceptación sobre todo entre los militares más jóvenes, ya que incluye desde los nuevos hábitos alimenticios a productos caseros, en un intento por mejorar su estado de ánimo ${ }^{16}$. 


\section{ALIMENTACIÓN ACTUAL EN EL EJÉRCITO DE TIERRA}

Todo lo relacionado con la alimentación del Ejército de Tierra se rige en este momento por el Manual Técnico. Alimentación en el Ejército de Tierra de $2001^{17}$. Según refiere el mencionado Manual, para la adquisición de los alimentos, el Administrador del Recurso de Alimentación expide los correspondientes Documentos de Retención de Crédito a favor de los Órganos de Contratación subordinados, que ejercerán la gestión y control de estos recursos presupuestarios ${ }^{18}$.

La alimentación de los soldados en los acuartelamientos suele estar a cargo de un servicio de alimentación, que prepara diariamente las tres comidas en su cocina, bien con sus propios medios o mediante una contrata externalizada, aunque también hay un número reducido de pequeñas unidades, a las que una empresa de catering les proporciona la comida preparada. Cuando hay ejercicios o maniobras el sistema varía, pues se puede cocinar en el acuartelamiento y llevar la comida en termos a los soldados, utilizar cocinas de campaña o bien emplear raciones de campaña, conocidas habitualmente como "raciones de previsión". La confección de minutas se realiza "teniendo en cuenta su valoración alimentaria en función al esfuerzo físico que tenga que realizar la tropa, la climatología de la zona y la estación del año. Se trata de que la fuerza reciba una alimentación equilibrada, ni sobrepasando ni faltando el aporte en calorías necesario"19.

\section{Normas para el empleo de los alimentos}

Como refiere el Manual Técnico, "el problema práctico de establecer una dieta equilibrada para la colectividad militar reside en determinar cualitativa y cuantitativamente los alimentos que han de componer la ración diaria del soldado, de acuerdo con las normas nutricionales establecidas y teniendo en cuenta para ello los siguientes factores: necesidades energéticas individuales, valor nutritivo de los alimentos y sistema de aprovisionamiento (ración en especie, en metálico o mixta)" ${ }^{\prime 20}$.

\section{Menús y suplementos}

Existen 32 menús distintos distribuidos en cuatro grupos en función de las cuatro estaciones, cada uno con 3.000 calorías/día correspondientes a las necesidades de la dieta básica del soldado o marinero, manteniendo el adecuado equilibrio entre los distintos principios inmediatos, minerales y vitaminas. Cada menú se compone de desayuno, que aporta 600 calorías, comida con 1.400 cal. y cena con 1.000 cal. Y aunque la ración reglamentaria de pan es de 400 gr./día, se supone que no es consumida totalmente, de forma que en cada módulo las cantidades de pan varían en función de los distintos platos que lo componen. Los menús de la dieta básica de 3.000 cal. están indicados cuando se trabaja en condiciones normales y clima medio, pero cuando hay mayor trabajo físico o temperaturas bajas se pueden añadir suplementos de 500 cal., de forma que con el aumento de uno o dos módulos sobre la dieta básica o Ración Normal (RN) se pueden transformar en RN-1 con 3.500 cal. o en RN-2 con 4.000 cal.

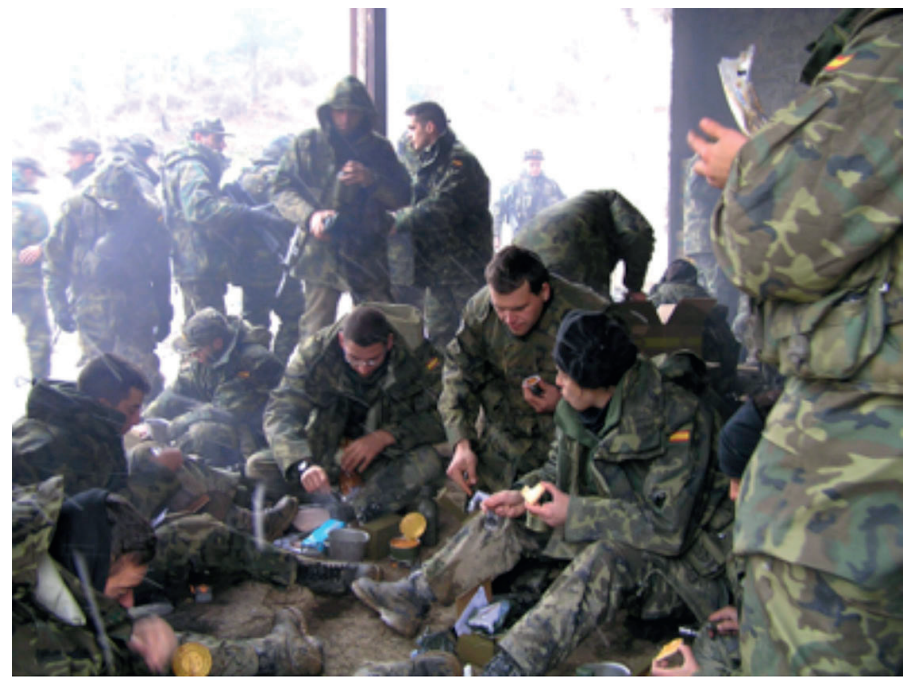

Figura 10. Cadetes comiendo raciones de previsión en Las Batiellas. Foto del autor.

Hay 10 modelos de suplementos que consisten en 100 gr. de pan, acompañado por embutido, caballa, sardinas en aceite, queso fundido o foie-gras y un zumo de naranja o manzana.

\section{Alimentación en maniobras y operaciones}

Las unidades militares disponen de cocinas de campaña adecuadas para confeccionar la alimentación en operaciones, ejercicios o maniobras, con el menaje necesario para cocinar y distribuir la comida a los soldados ${ }^{22}$. También cuentan con aljibes que cumplen la normativa vigente para almacenar agua en condiciones óptimas para el consumo humano y, además, tanto la tropa como las cocinas deben de disponer de pastillas o productos potabilizadores. Se contempla como referencia la cantidad de 17 litros hombre/día. Para cocinar en maniobras debe de haber abundante agua y detergentes para la limpieza de los

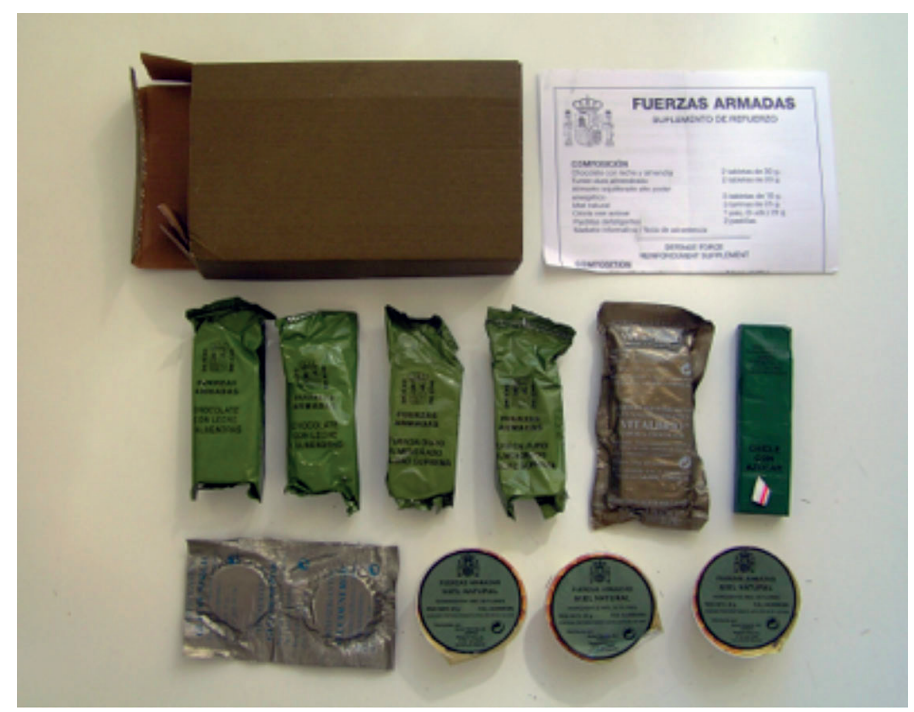

Figura 11. Contenido de un suplemento. Foto del autor. 
útiles y menaje de cocina, que deberán de ser correctamente eli$\operatorname{minados}^{23}$.

El suministro de los alimentos se puede realizar con productos en fresco o congelados, que las unidades confeccionarán en las cocinas de campaña, o bien surtir de alimentos elaborados, que con una mínima manipulación, generalmente el calentamiento, puedan ser servidos a la tropa. Los residuos se deberán de evacuar a basureros o lugares autorizados, para lo cual se dispondrá de cubos, palas, bolsas de basura y los vehículos necesarios para su traslado, ya que está totalmente prohibido su enterramiento ${ }^{24}$.

\section{Raciones especiales de campaña}

Otra modalidad de alimentación en maniobras es la ración especial de campaña, que es "el conjunto de alimentos necesarios para asegurar la capacidad operativa del combatiente, durante un periodo de tiempo determinado, normalmente un día". Las raciones pueden ser: individuales, de emergencia, colectivas y suplementos. La alimentación en campaña debe de atenerse a tres criterios fundamentales: ser fácil el abastecimiento, adaptada a satisfacer las necesidades derivadas de las circunstancias de la guerra y de fácil conservación, distribución y transporte.

La Ración Especial Individual es la que no necesita preparación conjunta, pudiendo ser consumida directamente por el soldado, debiendo de evitarse su uso continuado durante más de una semana, siempre que las circunstancias lo permitan. La mencionada ración consta de cinco paquetes: desayuno, $1^{\mathrm{a}}$ comida, o módulo A, $2^{\mathrm{a}}$ comida, o módulo $\mathrm{B}$ y dos módulos de pan-galleta de 100 gr./c.u., siendo los módulos A y B del mismo valor energético. Por otra parte, en este tipo de raciones existe una específica para musulmanes. La división en módulos facilita la combinación de las raciones y las posibilidades tácticas de la maniobra, ya que no precisan de cocinas, permitiendo al jefe de la unidad una mejor programación de la alimentación de su tropa. Hay cinco módulos diferentes de desayuno, comida y cena.

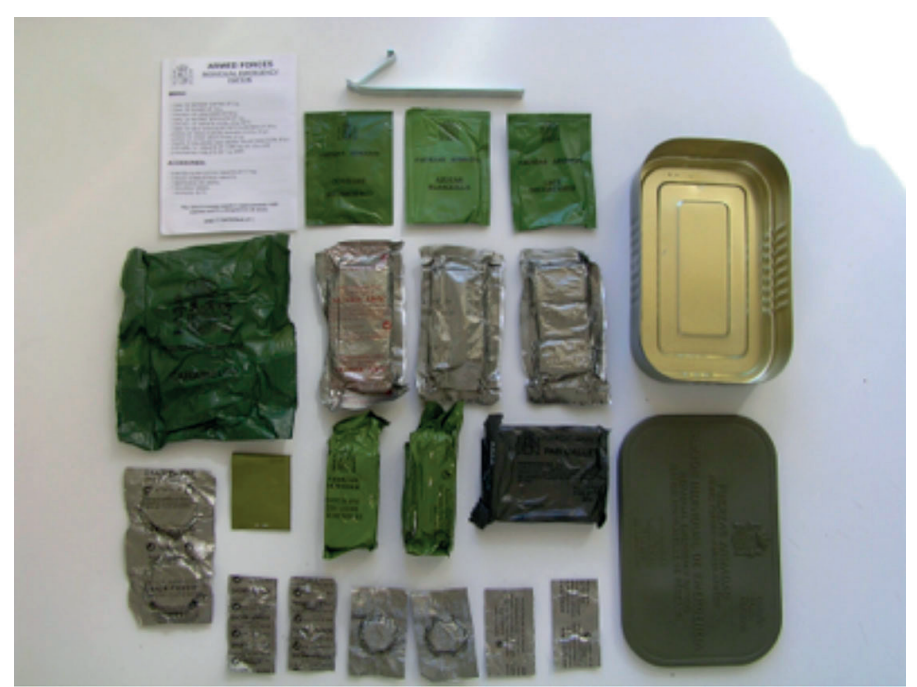

Figura 12. Ración Individual de Emergencia. Foto del autor.

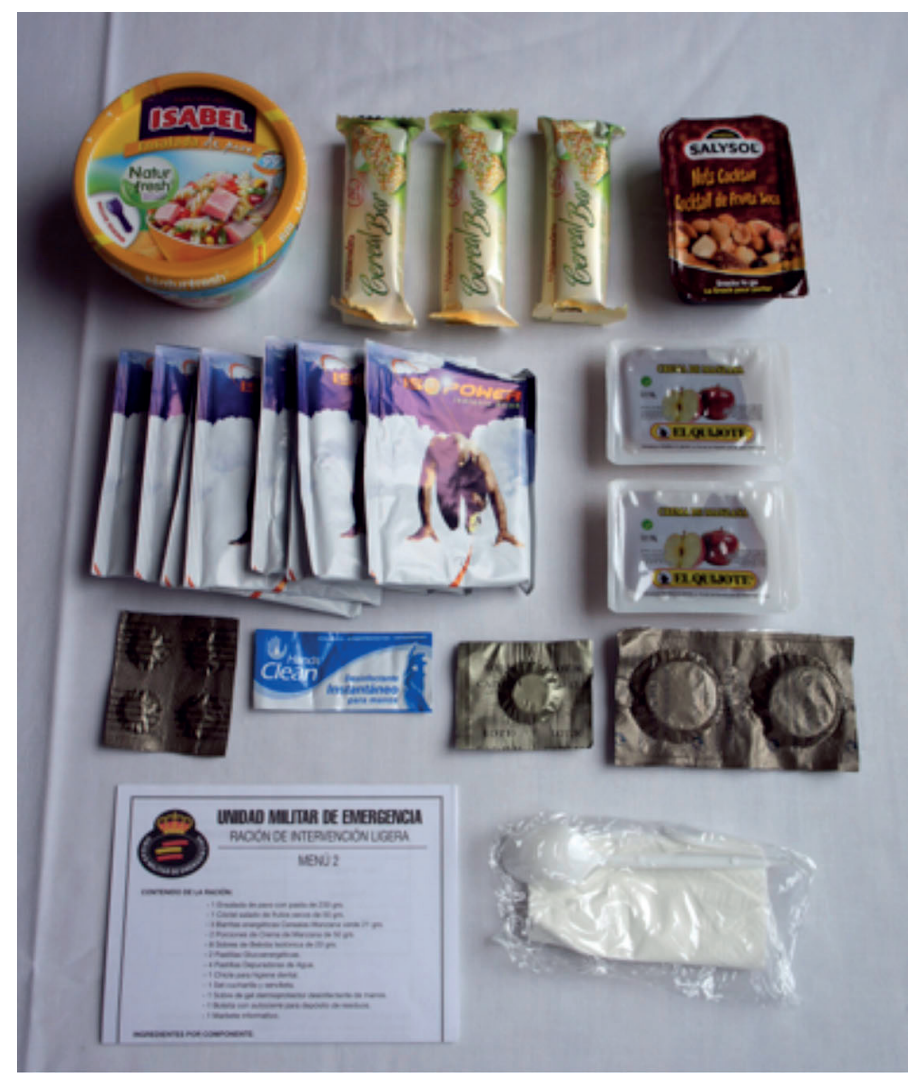

Figura 13. Ración de Intervención Ligera de la Unidad Militar de Emergencia. Foto del autor.

También existe la Ración de Emergencia, que no forma parte del régimen de alimentación establecido, pero que su función es el mantenimiento de la capacidad operativa del combatiente, cuando el suministro normal ha quedado interrumpido. Estas raciones deben de llevarlas los combatientes en periodos de operaciones.

Recientemente se ha vuelto a fabricar una Ración Especial Colectiva para 10 plazas, compuesta por desayuno, $1^{\text {a }}$ comida y $2^{\mathrm{a}}$ comida, que irán en módulos independientes. Estas raciones deben de ser sometidas a una preparación conjunta para su consumo, lo que implica que todos los componentes del pelotón deben de comer a la vez ${ }^{25}$. Y por último están los denominados Suplementos, que se añaden al suministro de raciones individuales o colectivas, como el pan fresco o el de larga duración ${ }^{26}$.

Según refiere el Manual Técnico, las reservas de raciones especiales de campaña serán las siguientes: el combatiente llevará siempre una ración de emergencia; la Compañía tendrá una ración especial individual completa por cada soldado; el Batallón dispondrá de una ración de emergencia y otra especial individual completa para cada soldado y una especial colectiva, más la de consumo del día, si se cocina de forma centralizada ${ }^{27}$, todo lo cual debe de proporcionar una autonomía de tres días a una unidad tipo Batallón, por si el suministro se viera interrumpido. A nivel Brigada y División debería haber una ración especial individual completa y otra colectiva por cada componente de las mismas, lo que en total proporcionaría una autonomía de cinco días a las mencionadas unidades. 
Tabla 1. Gasto energético de una persona de $65 \mathrm{~kg}$ en 24 horas en función del ejercicio físico.

\begin{tabular}{|l|c|c|c|c|}
\hline \multicolumn{1}{|c|}{ TIPO DE ACTIVIDAD } & $\begin{array}{c}\text { Actividad ligera } \\
\text { (kg/cal) }\end{array}$ & $\begin{array}{c}\text { Moderadamente } \\
\text { activa (kg/cal) }\end{array}$ & $\begin{array}{c}\text { Muy activa } \\
\text { (kg/cal) }\end{array}$ & $\begin{array}{c}\text { Excepcionalmente } \\
\text { activa (kg/cal) }\end{array}$ \\
\hline En reposo (8 horas) & 500 & 500 & 500 & 500 \\
En el trabajo (8 horas) & 1.100 & 1.400 & 1.900 & 2.400 \\
Actividad no profesional (8 horas) & $700-1.500$ & $700-1.500$ & $700-1.500$ & $700-1.500$ \\
Limites del gasto de energia (8 horas) & $2.300-3.100$ & $2.600-3.400$ & $3.100-3.900$ & $3.600-4.400$ \\
\hline Promedio (24 horas) & 2.700 & 3.000 & 3.500 & 4.000 \\
Promedio por kilogramo peso corporal & 42 & 46 & 54 & 62 \\
\hline
\end{tabular}

\section{Ejecución del sistema de alimentación en campaña}

La alimentación en campaña comprende dos aspectos: la distribución de las raciones a los consumidores y la reposición de las consumidas. La distribución de los alimentos se realizará en función de la situación táctica, pudiendo ser de tres formas: comidas colectivas confeccionadas a partir de víveres frescos, comidas confeccionadas con elementos elaborados o bien utilizar raciones de emergencia. Cuando se trata de comidas confeccionadas con víveres frescos, éstos se pueden distribuir directamente a las cocinas de campaña de Batallón o a las de cada Compañía $\mathrm{y}$, posteriormente, transportar la comida en termocontenedores a los soldados para evitar otras manipulaciones. Las raciones de emergencia se distribuirán a los soldados en situaciones de aislamiento o interrupción prolongada del suministro, considerando su consumo el último recurso ${ }^{28}$.

Hay que tener presente, que la alimentación de las unidades en ejercicios o maniobras sirve también para adiestrar a los miembros de las unidades logísticas de abastecimiento, a los encargados de la confección y distribución de las comidas y a todos los combatientes para ejercitarse en esta práctica. La reserva de raciones estará en cada Agrupación de Apoyo Logístico (AALOG) y, además, en el PCAMI existirá una reserva de raciones de campaña, determinada por la División de Logística del $\mathrm{EME}^{29}$.

\section{Estudio de las raciones individuales de combate (RIC)}

Para conocer detalladamente cómo son las raciones individuales de combate es imprescindible el estudio de los Pliegos de Prescripciones Técnicas (PPT), donde se establecen todos los requisitos exigidos a los fabricantes para el suministro de las diferentes raciones que contempla el Ejército de Tierra.

La Ración Individual de Combate o ración de previsión, como se la denominó en su momento, debe "ser suficiente y adecuada con un aporte total que cubra todas las necesidades nutrientes de un soldado durante el periodo de un día. Será fácil de calentar, sólida al transporte, adaptable a la mochila y de poco peso y volumen" 31 . La mencionada ración se compone de tres paquetes: desayuno, comida A y comida B, con diferentes menús, además del pan galleta o un sustitutivo. Irán embaladas en una caja de cartón ondulado, estanca al polvo y los artículos contenidos perfectamente inmovilizados para evitar golpes ${ }^{32}$. Las cajas deben de ir envueltas en una bolsa de poliéster color verde OTAN con plegado inglés y las inscripciones de los menús serán de diferentes colores para diferenciarlos ${ }^{33}$. A su vez, las raciones irán embaladas en cajas de transporte de cartón, que contendrán 20 desayunos ó 25 cuando se traten de comidas o cenas.

Los envases metálicos de las raciones serán en forma de tubo o de bote. Los botes de hojalata deben ir estañados, ser totalmente herméticos y con un sistema de apertura fácil. El color exterior será verde oliva grisáceo, salvo la tapa, que irá en color hojalata. El interior estará barnizado adecuadamente a cada tipo de conserva, pudiendo ir porcelanizado en blanco. Los envases no metálicos deben de estar fabricados a base de aluminio, litografiados con el escudo nacional, la leyenda Fuerzas Armadas, el logotipo del distribuidor, la denominación del producto, la información determinada por la legislación vigente y la fecha de consumo. La caducidad estará impresa en todos los envases de la ración, que para el desayuno será como mínimo de 18 meses y para las comidas de tres años a partir de la fecha de envasado. El PPT especifica cual debe ser la higiene de la producción y comercialización, el empleo de aditivos y que los organismos modificados genéticamente no superen el 0`9\%.

\section{Composición de los menús}

Como ejemplo se va a utilizar el menú $n^{\circ} 1$, cuyo desayuno consiste en un sobre de cacao en polvo de 18 gr., un tubo de leche condensada azucarada de 75 gr., un sobre de cereales con frutas y miel de 30 gr., un paquete de galletas dulces de 80 gr. y una chocolatina de 25 gr. La comida A-1 contiene un sobre de sopa de pollo con pasta de 13 gr., una lata de lentejas con chorizo y tocino de 300 gr., una lata de caballa en aceite de 120 gr. y una tarrina de crema de manzana de 50 gr. Y la comida B-1 contendrá un sobre de sopa de verduras de 20 gr., una lata de salchichas con tomate de 200 gr., una lata de pulpo al ajillo de 11 gr., una

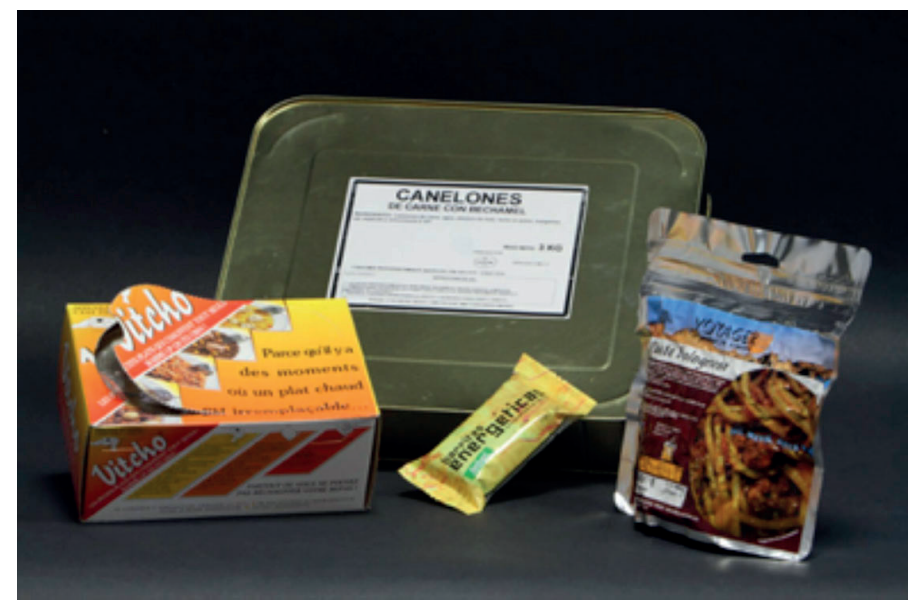

Figura 14. Nuevas raciones colectivas. 
Tabla 2. Contenido energético y principios inmediatos de las raciones del Ejército de Tierra.

\begin{tabular}{|c|c|c|c|c|c|c|c|c|}
\hline \multirow{4}{*}{ Desayuno } & \multicolumn{4}{|c|}{ RACIÓN NORMAL (RN) } & \multicolumn{4}{|c|}{ RACIÓN MUY ACTIVA (RN-1) } \\
\hline & Calorias & $\begin{array}{l}\text { Proteina } \\
(12 \%)\end{array}$ & $\begin{array}{l}\text { Lipidos } \\
(33 \%)\end{array}$ & $\begin{array}{l}\text { H de C } \\
(55 \%)\end{array}$ & Calorias & $\begin{array}{c}\text { Proteina } \\
(12 \%)\end{array}$ & $\begin{array}{l}\text { Lipidos } \\
(33 \%)\end{array}$ & $\begin{array}{l}\text { H. de C } \\
(55 \%)\end{array}$ \\
\hline & \multirow{2}{*}{600} & $17 \mathrm{cal}$. & $198 \mathrm{cal}$. & $330 \mathrm{cal}$. & \multirow{2}{*}{600} & $72 \mathrm{cal}$. & $198 \mathrm{cal}$. & $330 \mathrm{cal}$. \\
\hline & & $18 \mathrm{~g}$. & $22 \mathrm{~g}$. & $82,5 \mathrm{~g}$. & & $18 \mathrm{~g}$. & $22 \mathrm{~g}$. & $82,5 \mathrm{~g}$ \\
\hline \multirow{2}{*}{ Bocadillo } & & & & & \multirow{2}{*}{$250(1)$} & $30 \mathrm{cal}$. & $82,5 \mathrm{cal}$. & $137,5 \mathrm{cal}$. \\
\hline & & & & & & $7,5 \mathrm{~g}$. & $9,1 \mathrm{~g}$. & $34,3 \mathrm{~g}$ \\
\hline \multirow{2}{*}{ Comida } & \multirow{2}{*}{1.400} & $168 \mathrm{cal}$ & $462 \mathrm{cal}$. & $770 \mathrm{cal}$. & \multirow{2}{*}{1.400} & $168 \mathrm{cal}$ & $426 \mathrm{cal}$. & $770 \mathrm{cal}$. \\
\hline & & $42 \mathrm{~g}$ & $51,3 \mathrm{~g}$. & $192,5 \mathrm{~g}$. & & $92 \mathrm{~g}$. & $51,3 \mathrm{~g}$ & $192,5 \mathrm{~g}$ \\
\hline \multirow{2}{*}{ Merienda } & & & & & \multirow{2}{*}{$250(1)$} & $30 \mathrm{cal}$. & $82,5 \mathrm{cal}$. & 137,5 cal. \\
\hline & & & & & & $7,5 \mathrm{~g}$ & $9,1 \mathrm{~g}$. & $34,3 \mathrm{~g}$ \\
\hline \multirow{2}{*}{ Cena } & \multirow{2}{*}{1.000} & $120 \mathrm{cal}$. & $330 \mathrm{cal}$. & $550 \mathrm{cal}$. & \multirow{2}{*}{1.000} & $120 \mathrm{cal}$. & $330 \mathrm{cal}$. & $550 \mathrm{cal}$. \\
\hline & & $30 \mathrm{~g}$. & $36,4 \mathrm{~g}$ & $137.5 \mathrm{~g}$. & & $30 \mathrm{~g}$ & $36,4 \mathrm{~g}$ & $137,5 \mathrm{~g}$. \\
\hline \multirow{2}{*}{ TOTALES .... } & \multirow{2}{*}{3.000} & $360 \mathrm{cal}$. & $990 \mathrm{cal}$. & $1.650 \mathrm{cal}$. & \multirow{2}{*}{3.500} & $420 \mathrm{cal}$ & $1.155 \mathrm{cal}$. & $1.925 \mathrm{cal}$ \\
\hline & & $90 \mathrm{~g}$. & $109,7 \mathrm{~g}$. & $412,5 \mathrm{~g}$. & & $105 \mathrm{~g}$ & $127,9 \mathrm{~g}$. & $481,1 \mathrm{~g}$. \\
\hline
\end{tabular}

(1) Bocadillo y merienda pueden agruparse en un solo suministro de mantana o tarde (500 cal)

gr., mientras que la ración completa de pan pesa $200 \mathrm{gr}^{35}$.

El resto de raciones contienen de una forma general lo siguiente: la comida A-2 pote gallego y calamares en su tinta; A-3 cocido madrileño y atún en aceite, A-4 judías con chorizo y sardinas en aceite; A-5 ensalada campera y magro de cerdo, mientras que las cenas llevan: la B-2 albóndigas con guisantes y sardinas con tomate; B-3 carne de vacuno en salsa y caballa en aceite, B-4 carne de vacuno con guisantes y atún en aceite y la B-5 judías verdes con jamón y calamares en aceite como alimentos principales.

También existe una ración individual de combate para personal musulmán, que es similar a la ya comentada anteriormente, aunque para distinguirlas el color de la rotulación va en amarillo y en un círculo se ve un cerdo tachado por un aspa. De este modelo sólo se fabrican dos menús. El desayuno contenía una bolsa de té de 2 gr., un sobre de café soluble de 2 gr., un tubo de leche condensada azucarada de 75 gr., un paquete de galletas dulces de 75 gr., una tarrina de confitura de frambuesa o de albaricoque de 25 gr. y una tarrina de miel de 25 gr., aunque dada la similitud al resto de desayunos, se ha dejado de fabricar. La comida contiene un sobre de sopa de pollo con pasta de 13 gr., una lata de 300 gr. de judías con tomate o bien de garbanzos guisados, una lata de 120 gr. de caballa o de calamares en aceite y una tarrina de crema de manzana o de membrillo de 50 gr. Y la

lata de melocotón en almíbar de 190 gr. y una lata de paté de 60 gr. Además se acompañará de dos paquetes de pan galleta de 100 gr. o bien dos paquetes de 130 gr. de pan de larga duración, uno para cada comida ${ }^{34}$.

Los complementos del desayuno son: dos pastillas depuradoras de agua con dicloroisocianurato sódico de $17 \mathrm{mg}$. y excipiente, dos pastillas de combustible sólido en blíster o cinta termoplástica, que deben de arder entre 6 y 9 minutos/pastilla en climatología normal, una pastilla hidratante compuesta por $500 \mathrm{mg}$. de cloruro sódico, $36 \mathrm{mg}$. de cloruro potásico y $200 \mathrm{mg}$. de carbonato cálcico, que irá en un blíster o cinta termoplástica, un chicle de higiene dental, un estuche de cerillas, un hornillo, una bolsa de papel celulosa de 10 hojas, una nota informativa, un cepillo dental con un sobre de crema dentífrica fluorada y un sobre desinfectante de manos. Mientras que los complementos de las comidas A y B son: dos pastillas depuradoras de agua, tres pastillas de combustible sólido, dos pastillas hidratantes, dos pastillas defatigantes, una pastilla de Vitamina $\mathrm{C}$, un chicle de higiene dental, un estuche de cerillas, un hornillo, un abrelatas, una bolsa de papel celulosa con 10 hojas, una nota informativa y un sobre desinfectante de manos. El peso de la caja de desayuno es de 228 gr., el de la comida 490 gr. y el de la cena 543 cena contiene un sobre de sopa de verduras de 20 gr., una lata de 200 gr. de carne de vacuno bien en salsa o con guisantes, una lata

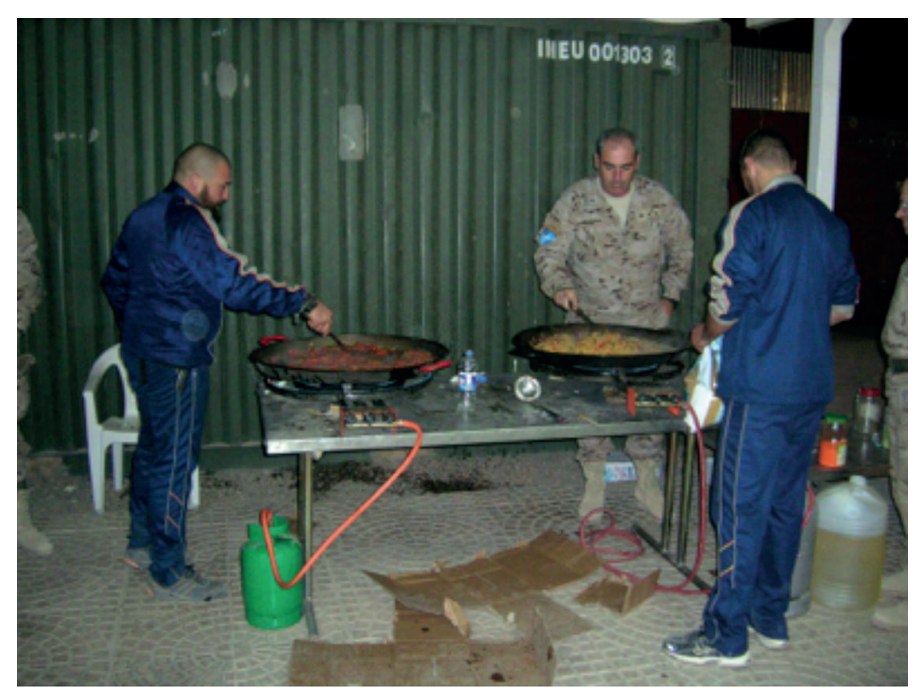

Figura 15. Militares españoles preparando una paella en "Camp Ston". Foto Fernando Piñol 2012. 


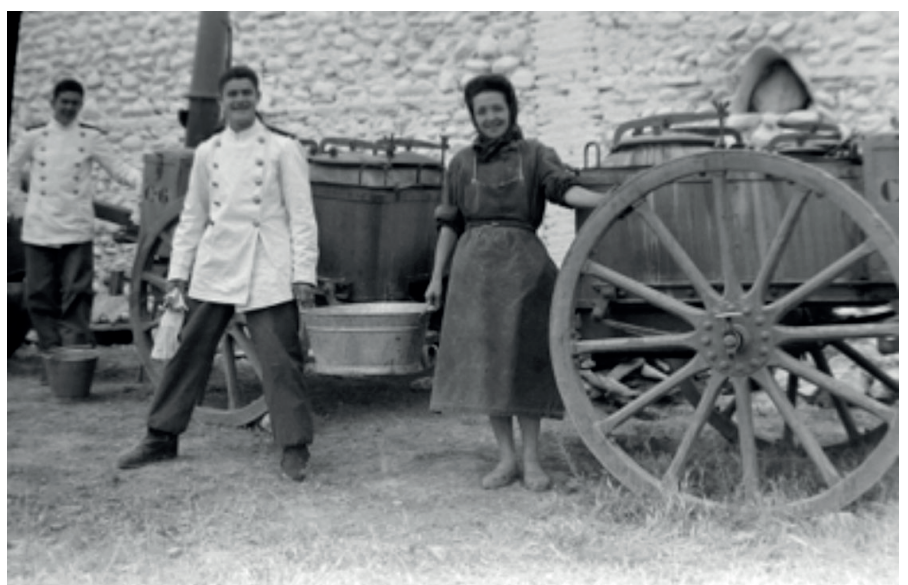

Figura 16. Cocina de campaña en el campo de maniobras de San Gregorio en 1948. Archivo fotográfico de la Academia General Militar.

de 115 gr. de atún blanco en aceite o bien de sardinas con tomate, una lata de 30 gr. bien de paté de ave o de atún y de postre una lata de 190 gr. de melocotón en almíbar o bien de cocktail de frutas. Estas raciones van con el pan y los complementos correspondientes y su peso será de 1.461 gr. el menú $\mathrm{n}^{\circ} 1$ y de 1.459 gr. el menú $n^{\circ} 2^{36}$.

Como ya se ha comentado, todas las raciones van acompañadas de pan de larga duración o de pan galleta. Éste último irá en paquetes de 100 gr., conteniendo un mínimo de cinco galletas rectangulares, confeccionadas con harina de trigo, grasa comestible vegetal, azúcar, glucosa, sal y aditivos. Irán protegidas con una bandeja de cartón ondulado y cerrado en forma de $\mathrm{O}$, como protector antichoque, y todo envuelto herméticamente en plástico polipropileno de color verde oliva convenientemente etiquetado. Se transportan en cajas de cartón, que contendrán 48 raciones ${ }^{37}$. Por su parte, el pan de larga duración se fabrica con harina de trigo, agua, sal, levadura, grasas comestibles, azúcares comestibles y condimentos. Es de corteza no crujiente, textura blanda y el contenido máximo de humedad será del 38\%. Se embalan de dos en dos protegidos por un envase flexible de alta barrera color verde oliva, con la impresión correspondiente. Se transporta en cajas de cartón con 48 raciones, siendo su caducidad 24 meses a partir del envasado ${ }^{38}$.

A todas estas raciones se les puede añadir el denominado Refuerzo Especial o Suplemento Energético, que es un refuerzo alimenticio para situaciones en las que es necesario un mayor aporte calórico para el combatiente, mediante alimentos concentrados y de alto valor energético. Los alimentos serán: dos tabletas de chocolate con leche y almendras de 30 gr./u., dos de turrón almendrado duro de 20 gr./u., una de alimento equilibrado de alto valor energético de 30 gr., un tubo de miel natural con 75 gr. o bien tres tarrinas de 25 gr., un paquete con cinco láminas de chicle con azúcar y dos pastillas defatigantes de glucosa, carnitina y arginina para utilizar en situaciones de gran actividad física. El valor energético será de 4.191 Kilojulios, con un 5’15\% de proteínas, 30'07 de lípidos y 64'78 de hidratos de carbono, siendo el peso de la ración de 275 gr. Irán envasados en una caja de cartón envuelta en una bolsa de poliéster con plegado inglés, que permita una perfecta adaptación a la caja e impermeabiliza-
Tabla 3. Asignación de raciones en función del tipo de ejercicio.

\begin{tabular}{|l|l|}
\hline \multicolumn{1}{|c|}{ EJERCICIO } & \multicolumn{1}{|c|}{ RACIONES } \\
\hline TIPO ALFA & $\begin{array}{l}\text { 1 Ración E. Individual Completa. } \\
\text { 1 Ración E. Colectiva de elementos elaborados. }\end{array}$ \\
\hline TIPO BETA & $\begin{array}{l}\text { 1 Ración E. Individual Completa. } \\
\text { 1 Ración E. Colectiva de elementos elaborados. }\end{array}$ \\
\hline TIPO GAMMA & 1 Ración E. Individual Completa. \\
\hline TIPO DELTA & 1 Ración E. Colectiva de elementos elaborados. \\
\hline
\end{tabular}

ción total, mientras que la rotulación será como las raciones anteriores. Se trasportan en cajas de cartón con 40 suplementos ${ }^{39}$.

Para situaciones especiales está la Ración Individual de Emergencia, prevista para sostener la capacidad operativa del personal militar al menos 24 horas, que se utiliza cuando el suministro queda interrumpido. Cada ración contiene un sobre de café soluble de 2 gr., un sobre de azúcar de 10 gr., un paquete de pan galleta de 30 gr., un sobre de consomé instantáneo de 4 gr., seis caramelos de 6 gr./u., una tableta de chocolate con leche y almendra de 30 gr., dos tabletas de turrón duro almendrado de 20 gr./u., dos tabletas de carne desecada masticable de 9 gr./u., con proteína de soja, hidrolizado proteico, grasas comestibles vegetales, maltodrextrinas y aditivos autorizados, dos tabletas de alimento equilibrado de alto valor energético sabor chocolate de 30 gr./u., con azúcar de caña dextrosa, grasas vegetales comestibles, proteínas de soja, aroma y extracto natural de coco o cacao y aditivos, y dos comprimidos de Vitamina $\mathrm{C}$ de 1 gr./u. Como complementos llevará una pastilla hidratante, cuatro pastillas depuradoras de agua de $17 \mathrm{mg}$ de agente activo, dos pastillas de combustible sólido, un estuche de cerillas con 20 unidades, una pinza soporte en chapa de acero, un sobre con desinfectante de manos y un marbete informativo.

El envase de estas raciones será de hojalata, que servirá a su vez como cacillo para calentar el café o el consomé instantáneo, aplicándole el soporte. Irá cerrado con una tapa plástica ajustada, que cierre a presión y permita la apertura o cierre cuantas veces sea necesario. Su envuelta exterior será una bolsa termo-

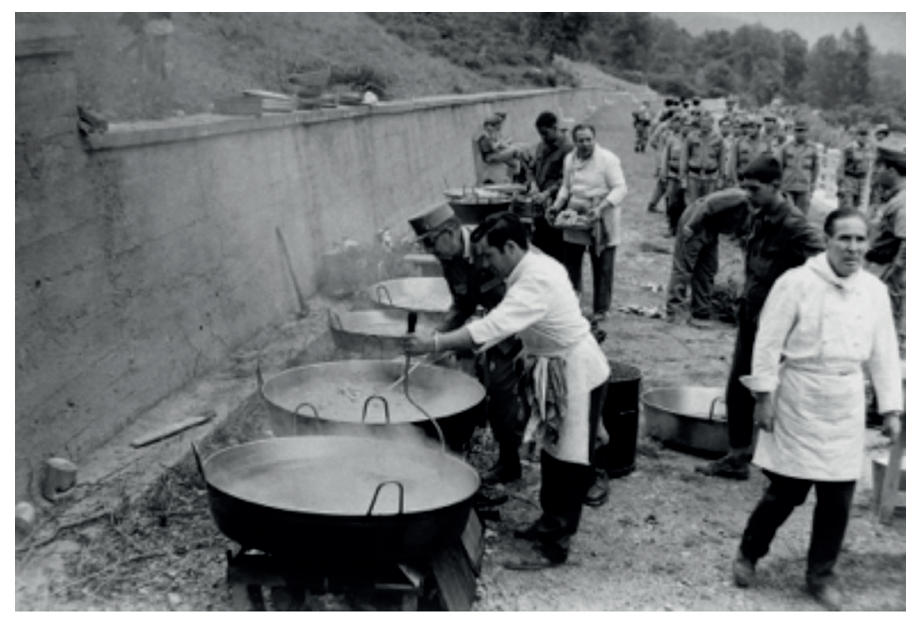

Figura 17. Cocina improvisada en unas maniobras en 1970. Archivo fotográfico de la Academia General Militar. 
Tabla 4. Valor energético de los diferentes menús.

\begin{tabular}{|c|c|c|c|c|c|}
\hline Menús & $\mathrm{N}^{\circ} 1$ & $\mathrm{~N}^{\circ} 2$ & $\mathrm{~N}^{\circ} 3$ & $\mathrm{~N}^{\circ} 4$ & $\mathrm{~N}^{\circ} 5$ \\
\hline Proteínas & $16^{\prime} 10^{\prime} \%$ & $17^{\prime} 54 \%$ & $17^{\prime} 30 \%$ & $18^{\prime} 95^{\prime} \%$ & $16^{\prime} 21^{\circ} \%$ \\
\hline Lípidos & $36^{\prime} 35^{\prime} \%$ & $38^{\prime} 55^{\prime} \%$ & $34^{\prime} 96^{\prime} \%$ & $35^{\prime} 59^{\prime} \%$ & $40^{\prime} 69^{\prime} \%$ \\
\hline H. de Carb. & $47^{\prime} 55^{\prime} \%$ & $43^{\prime} 92^{\prime} \%$ & $47^{\prime} 74 \%$ & $45^{\prime} 47^{\prime} \%$ & $43^{\prime} 10^{\prime} \%$ \\
\hline Kilojulios & 15.110 & 14.612 & 14.431 & 14.723 & 14.558 \\
\hline Musulmán & - & - & - & - & - \\
\hline Proteínas & $17^{\prime} 85^{\prime} \%$ & $16^{\prime} 36 \%$ & - & - & - \\
\hline Lípidos & $32^{\prime} 72^{\prime} \%$ & $35^{\prime} 39^{\prime} \%$ & - & - & - \\
\hline H. de Carb. & $49^{\prime} 43^{\prime} \%$ & $48^{\prime} 25^{\prime} \%$ & - & - & - \\
\hline Kilojulios & 13.787 & 14.241 & - & - & - \\
\hline
\end{tabular}

soldada, hermética y estanca, cerrada al vacío. La etiquetación será similar a las mencionadas anteriormente, con una caducidad de 24 meses a partir del envasado, siendo su peso de $395 \mathrm{gr}$. El valor energético es de $4.312 \mathrm{Kcal}$, con un $10{ }^{\circ} \%$ de proteínas, $35{ }^{\prime} \%$ de lípidos y 53’9\% de hidratos de carbono. La ración se calentará con pastillas de combustión ${ }^{40}$.

Por su parte, el Batido de Alto Contenido en Proteínas es un producto alimenticio especial en polvo, elaborado con azúcares, proteínas y grasas vegetales, al que hay que añadirle agua para su consumo. Contiene sacarosa, lecitina de soja, leche en polvo, proteína aislada de soja, cacao o extracto de fresa en polvo, aroma de cacao o de fresa y excipiente. La ración consta de dos sobres de 120 gr., uno de sabor a chocolate y otro a fresa, envasados en una bandeja de aluminio cerrada por una lámina de

Tabla 5. Niveles de alimentación en operaciones.

\begin{tabular}{|c|c|c|}
\hline NIVELES & SITUACIÓN TÁCTICA & ALIMENTACIÓN \\
\hline 1 & $\begin{array}{l}\text { - Alta intensidad } \\
\text { - Sin pausas operacionales } \\
\text { - Rutas de abastecimiento no } \\
\text { seguras }\end{array}$ & $\begin{array}{l}\text { - RIC frias } \\
\text { - RIC autocalentables }\end{array}$ \\
\hline 2 & $\begin{array}{l}\text { - Alta intensidad } \\
\text { - Pequeñas pausas } \\
\text { operacionales } \\
\text { - Rutas de abastecimiento no } \\
\text { seguras }\end{array}$ & $\begin{array}{l}\text { - RIC para calentar } \\
\text { - Posible refuerzo de pan y } \\
\text { fruta }\end{array}$ \\
\hline 3 & $\begin{array}{l}\text { - Relativa estabilidad } \\
\text { - Largas pausas operacionales } \\
\text { - Rutas de abastecimiento no } \\
\text { seguras }\end{array}$ & $\begin{array}{l}\text { - Raciones } \\
\text { (necesario colectivas } \\
\text { campaña) }\end{array}$ \\
\hline 4 & $\begin{array}{l}\text { - Mayor estabilidad } \\
\text { - Largas pausas operacionales } \\
\text { - Rutas de abastecimiento } \\
\text { seguras }\end{array}$ & $\begin{array}{l}\text { - Raciones colectivas } \\
\text { (necesario cocinas de } \\
\text { campaña) } \\
\text { - Posible refuerzo de } \\
\text { productos frescos }\end{array}$ \\
\hline 5 & - Situación de estabilización & - Externalización \\
\hline $\begin{array}{l}\text { SITUACIONES } \\
\text { PARTICULARES }\end{array}$ & $\begin{array}{l}\text { Operaciones en zonas: } \\
\text { - de montaña } \\
\text { - tropicales } \\
\text { - desérticas } \\
\text { - contaminadas, etc. }\end{array}$ & $\begin{array}{l}\text { Raciones y refuerzos ad } \\
\text { hoc (liofilizadas, batidos } \\
\text { de alto contenido } \\
\text { energético, etc.) }\end{array}$ \\
\hline
\end{tabular}

aluminio termosellada. Se embalan en cajas de cartón con 56 raciones de dos sobres. La caducidad será de 36 meses a partir de la fecha de embasado $^{41}$.

\section{Raciones particulares}

Además de las raciones ya comentadas existen otras, como, por ejemplo, las que utiliza la Unidad Militar de Emergencias (UME), que dispone de dos modelos: la Ración de Intervención en Campaña (RIC) y la Ración de Intervención Ligera (RIL). Esta última se compone de una ensalada de pavo con pasta de 230 gr., un cóctel salado de frutos secos de 50 gr., dos barritas energéticas de Cereales-Manzana verde de 21 gr., dos porciones de Crema de Manzana de 50 gr., ocho sobres de bebida isotónica de 20 gr., dos pastillas glucoenergéticas, cuatro pastillas depuradoras de agua, un chicle de higiene dental, un set de cucharilla y servilleta, un sobre de gel dermoprotector desinfectante de manos, una bolsita con autocierre para depósito de residuos y un marbete informativo. Esta ración tiene un valor energético de $1.667 \mathrm{Kcal}$., con $25^{\prime} 90$ gr. de proteínas, 30 gr. de hidratos de carbono y 37'60 gr. de grasas. Las dos raciones tienen sus refuerzos correspondientes, por ejemplo, el de invierno para RIL, menú $\mathrm{n}^{\circ} 2$, que se compone de un capuchino autocalentable de $200 \mathrm{ml}$., cuatro paquetes de galletas camperas de 24 gr., un pan galleta de 55 gr., un paté de pato al oporto de 65 gr., un set de 3 cubiertos de plástico, un chicle para higiene dental, un paquete de pañuelos de celulosa de 10 unidades, una bolsita con desinfectante instantáneo de manos y otra para depósito de residuos. Su valor energético es de 913'4 Kcal., con 23’3 gr. de proteínas, $136^{\prime} 6$ gr. de hidratos de carbono y 30,4 gr. de grasas. Estas raciones van en una caja de cartón de color amarillo con el escudo de la Unidad, nombre de la ración, del distribuidor y fecha de consumo, que a su vez, va envuelta en una bolsa de celofán transparen$\mathrm{te}^{42}$. Los componentes de la UME llevan tres raciones por persona/ día y agua, entre 6 y 10 litros por persona/día. Hay que comentar, que en estas raciones, al ser de carácter "no táctico", usan productos y marcas comerciales de uso civil.

$\mathrm{Y}$ para situaciones diferentes, como operaciones especiales, zonas tropicales o ambientes contaminados, se dispondrá de raciones y re- 
fuerzos especiales de más de 1.000 calorías. Por ejemplo, para operaciones en montaña existen las raciones liofilizadas ligeras de marcha y para soldados que se encuentren operando en un supuesto ataque nuclear, biológico o químico, están las raciones de emergencia en ambiente NBQ con batidos de alto contenido en proteínas.

\section{Propuesta para un nuevo modelo de alimentación en campaña}

Después de utilizar las raciones especiales de campaña más de veinte años en territorio nacional y en misiones en el extranjero, pareció oportuno hacer una revisión, de forma que en el mes de abril de 2011 se celebró en la Academia Logística de Calatayud (ACLOG) el Seminario "Alimentación en campaña", con objeto de mejorar la nutrición del personal destacado en las Posiciones Avanzadas de Combate en Afganistán, decidiendo volver a confeccionar raciones colectivas envasadas en latas compactas de fácil manejo, que sirviesen para comer tanto en caliente como en frío. Las nuevas raciones, previstas para 10 ó 12 personas, se presentarán en dos latas de $3 \mathrm{Kg}$. cada una, con primeros y segundos platos, completándose la ración con pan y fruta. Para su fabricación se ha creado una Unión Temporal de Empresas formada por Jomipsa, Alonso Hipecas y Teógenes Ruiz, que deberán utilizar para su confección productos españoles.

El formato rectangular de la lata permite almacenarlas en un palé uniforme, que requiere menos medios para su transporte desde el territorio nacional a Afganistán, donde se deben de conservar en contenedores refrigerados a $18^{\circ} \mathrm{C}$ hasta ser llevadas a las posiciones, siendo su caducidad de tres años. Los nuevos menús son los siguientes: $\mathrm{n}^{\mathrm{o}} 1$, cocido madrileño y albóndigas de pollo con guarnición; $\mathrm{n}^{\circ} 2$, ensalada de pasta con atún y hamburguesas de vacuno con tomate; $\mathrm{n}^{\circ} 3$, ensalada campera y pollo en escabeche; $\mathrm{n}^{\circ} 4$, macarrones boloñesa de pollo y salchichas tipo alemán con tomate; $\mathrm{n}^{\circ} 5$, fabada asturiana y magro de cerdo con pisto; $n^{\circ} 6$, espagueti boloñesa y pollo estofado; $n^{\circ} 7$, ensalada de alubias con atún y codillo confitado; $\mathrm{n}^{\circ} 8$, canelones de carne con bechamel y estofado de ternera; $\mathrm{n}^{\circ} 9$, patatas guisadas con carne de cerdo y atún con tomate y $\mathrm{n}^{\circ} 10$, menestra de verduras y salchichas tipo alemán con tomate. "Una vez calentado, se sirve en plato y, psicológicamente, el efecto es el de que se acaban de cocinar" 43

Como ya se ha comentado anteriormente, las raciones de campaña se han utilizado en misiones en el extranjero desde el primer momento y, aunque con el tiempo los campamentos y las bases han dispuesto de sus propias cocinas fijas, la ración ha sido imprescindible para los militares que se desplazan en convoyes o que permanecían en posiciones alejadas. En Bosnia, en el año 1993, se comía de ración y siempre se llevaban a bordo de los vehículos $^{45}$. Y al año siguiente el destacamento de Dracevo estuvo comiendo durante doce días de ración tras el bombardeo de su cocina. Posteriormente, el contingente español enviado a Irak en el año 2004, inicialmente, tuvo que comer de ración de previsión, aunque el problema fue su conservación por el excesivo calor ambiental, ya que precisaban camiones isotermo. La situación varió cuando se instalaron cocinas en las bases "Al Andalus" en Han Nayaf y "Base España" en Diwaniya, que prepararon alimentación convencional hasta la retirada ${ }^{46}$.
En Afganistán tanto la base de Herat como la de "Ruy González de Clavijo" de Qala i Naw han dispuesto de cocinas para confeccionar los menús de los militares, pero no así en los puestos avanzados de combate (COP), como 'Fort Rickets', en Moqur o en el campamento "Bernardo de Gálvez", en Ludina, donde se comía de ración de campaña, aunque para hacerlas más apetecibles, se juntaban todas para calentarlas. El pan era el de las raciones, aunque cuando llegaba algún convoy solía traer pan convencional o pan afgano. En los COP puntualmente preparaban pasta o arroz aderezado con las propias raciones para romper la monotonía de la comida. Precisamente es para estos destacamentos para los que se diseñaron las nuevas raciones colectivas.

Pero en Afganistán el Ejército de Tierra también ha colaborado con los Equipos Operativos de Asesoramiento y Enlace (OMLT) para instruir al Ejército Nacional Afgano (ANA), habiendo militares españoles en "Camp Arena" y en "Camp Ston", donde la comida era la del ejército estadounidense, disponiendo también de raciones españolas para los recorridos en vehículo por la "Ring Road", aunque lo habitual era recalar en las bases avanzadas, donde se comía o cenaba del catering de la base ${ }^{47}$. Y por último, mencionar la base "Miguel de Cervantes", en Líbano, en la que hay instalaciones donde se cocina diariamente.

\section{Ejemplo de funcionamiento de un Servicio de Alimentación del Ejército de Tierra}

Como ejemplo del funcionamiento de un servicio de alimentación en un acuartelamiento se va a utilizar la Academia General Militar de Zaragoza (AGM), que a pesar de ser un centro de enseñanza, todo lo relativo a la alimentación es similar a cualquier unidad del Ejército de Tierra. La AGM siempre ha dispuesto de cocinas para preparar la alimentación de cadetes y tropa, pero cuando se salía de maniobras al campo de San Gregorio, la comida se confeccionaba en cocinas de campaña, hasta que se construyó el comedor con su cocina en el Campamento de $\mathrm{M}^{\mathrm{a}}$ Cristina, prescindiendo de las cocinas de campaña. Cuando los cadetes se desplazaban al Pirineo a efectuar las prácticas de montaña, la comida se preparaba en cocinas improvisadas a la

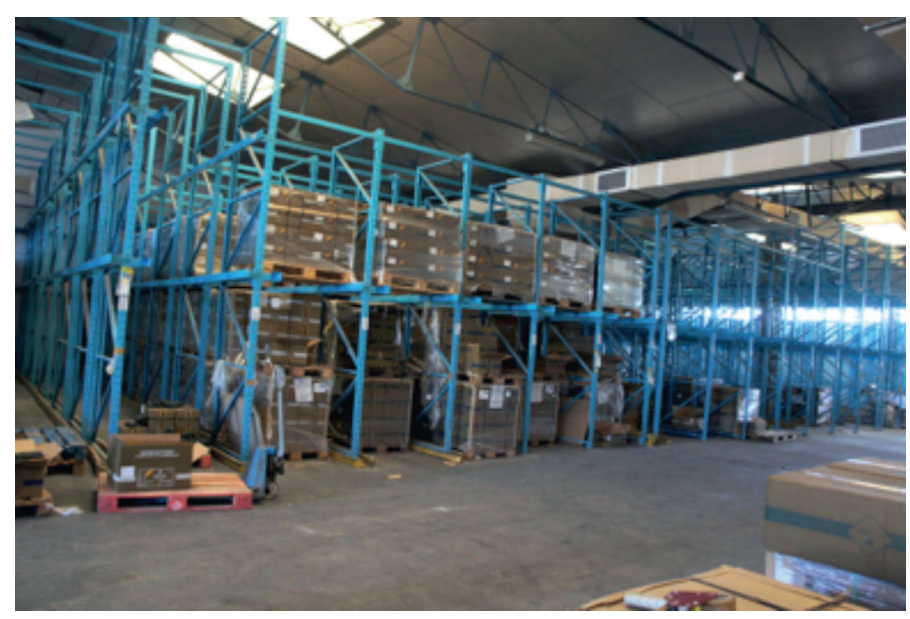

Figura 18. Almacén de raciones en la AALOG de Zaragoza. Foto del autor noviembre 2012. 


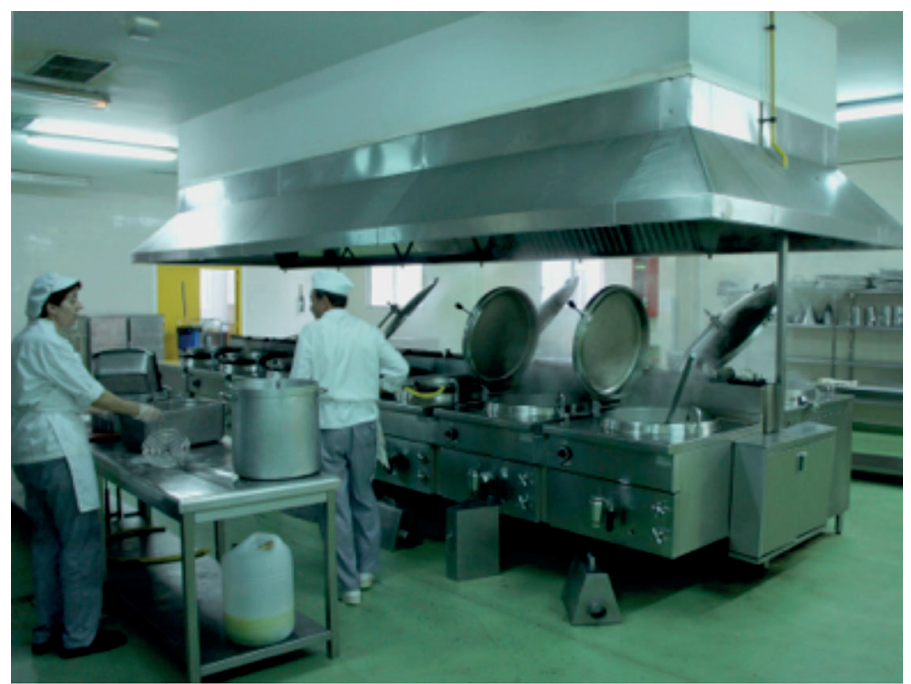

Figura 19. Cocinas de la Academia General Militar. Foto del Autor. Noviembre 2012.

intemperie, que siempre han estado en manos de cocineros civiles, los famosos maestros, ayudados por rancheros, soldados de reemplazo que aprendían el oficio y que alguno de ellos al licenciarse seguía trabajando como cocinero en el Ejército.

En el momento actual, el Servicio de Alimentación dispone de personal de cocina profesional civil y militar ${ }^{48}$, que confecciona toda la alimentación de los cadetes y cuando salen de maniobras, la Jefatura de Estudios es la que decide cual va a ser el modo de alimentación. Como la AGM ya no dispone de cocinas de campaña, la alimentación se prepara en la cocina y se transporta en termos al lugar en donde se encuentran los cadetes, siempre que estén en San Gregorio o en los montes de Zuera, aunque este sistema sólo se puede utilizar cuando se come en grupo, ya que la comida debe ser servida de una vez. En este momento se preparan diariamente 1.100 raciones con un coste de 6'80 euros/ración, frente a los 16 de las raciones de previsión.

En caso de que el ejercicio obligue a mantener dispersos a los cadetes, se prepara la ración en frío, que consiste en una bolsa con dos bollos de pan, una lata de coloniales, embutido envasado al vacío, una pieza de fruta, barras energéticas, que suelen ser de chocolate, caramelos, un refresco y un botellín de agua, que se puede consumir sin necesidad de estar juntos y en el momento que apetezca. Y, por último, está la utilización de raciones de campaña, que es parte importante de la instrucción de los cadetes, pues deben de llevarlas encima y acostumbrarse a su consumo. Para el uso de raciones de campaña, se hace una previsión anual del número que van a necesitar durante el curso y llegado el momento de utilizarlas, se recogen en la AALOG 41 y se les entrega al Batallón de Alumnos ${ }^{49}$.

Hay que comentar, que las AALOG recibirán el cálculo anual de raciones necesarias de todas las unidades de su influencia, solicitando la reposición de las mismas para su almacenamiento y distribución entre sus unidades en territorio nacional. Estas Agrupaciones disponen de las instalaciones adecuadas para el almacenamiento de las raciones que les entreguen los contratistas y sólo las distribuyen cuando van a ser consumidas. Para gestionar las raciones que se van a utilizar en operaciones hay un almacén en cada uno de los Órganos de Apoyo Logístico de cada zona, que cubrirá las necesidades de las unidades desplegadas en el extranjero y distribuirán las raciones a las unidades que lo soliciten para consumo ${ }^{50}$. La contratación de las raciones de campaña corresponde al PCAMI.

\section{COLOFÓN}

Con la generalización del uso de raciones de campaña desde los años noventa del siglo pasado se simplificó mucho todo lo concerniente a la alimentación en ejercicios y maniobras, ya que para unos pocos días era costoso emplear una cocina de campaña con su personal y las raciones en frío han dado más de un problema, por la falta de condiciones de conservación. Por el contrario, las nuevas raciones de campaña con sus envoltorios estancos, dan mucha más garantía de conservación y agilidad para su distribución y consumo, aunque el uso prolongado pueda crear otros problemas, como el cansancio ante la repetición de menús o las molestias digestivas.

\section{AGRADECIMIENTOS}

D. Luis Arias Ortega, comandante de Intendencia, Unidad de Estudios, Proyectos y Laboratorio, Parque y Centro de Abastecimiento de Material de Intendencia. Mando de Apoyo Logístico / DISA. D. Juan Covas Calafell, teniente coronel de Intendencia, jefe del Servicio de Alimentación de la AGM. D. Rafael Tinahones García, teniente coronel de Caballería, analista de logística de la Sección de Materiales de la DIDOM (MADOC). Presidente del grupo de estudio para la mejora de la alimentación en campaña

\section{BIBLIOGRAFÍA}

1. Pringle Mr. "Caballero Baronet de la Gran-Bretaña y Médico ordinario de la Reyna”. Observaciones acerca de las enfermedades del exército En los campos y guarniciones, con las memorias sobre las sustancias sépticas y anti-sépticas, leídas à la Sociedad Real. Madrid: 1775. La $7^{\mathrm{a}}$ edición la tradujo del francés al español Juan Galisteo.

2. Los franceses decían que en España todo olía y sabía a rancio, ya que se cocinaba con tocino conservado en sal, incluso el aceite de oliva, no refinado como el actual, sabía a rancio. Arcarazo García L. A. Lorén Trasobares Ma . P. Barbastro y su Partido durante la Guerra de la Independencia, 1808-1814. Huesca: 1994, p. 169.

3. Memorias del Mariscal Suchet sobre sus campañas en España 1808-1814. Zaragoza: 2012, p. 231.

4. Arcarazo García L A. La asistencia sanitaria en Zaragoza durante la Guerra de la Independencia Española, 1808-1814. Zaragoza: 2007.

5. Fernández Bastarreche F. "El servicio militar en la España del siglo XIX Una epidemia de los tiempos contemporáneos”. Historia 16, 140, pp. 27-36.

6. Ibíd., pp. 34-36.

7. Arcarazo García L. A. Lorén Trasobares Ma . P. El Santo Hospital de San Julián mártir y Santa Lucía y otros hospitales de Barbastro. Huesca: 2000, p. 228.

8. Fernández Bastarreche F. Op. Cit., p. 36.

9. Quevedo y Medina R. Notas a la vista. Tratado teórico-práctico de los productos alimenticios que son objeto del comercio y de que hace uso el Ejército en paz y en campaña. Madrid: 1894.

10. El pan galleta es pan sin levadura.

11. Quevedo y Medina R. Op. Cit., pp. 435-438. 


\section{LA. Arcarazo García}

12. El Cuerpo de Administración Militar en 1911 se desdobló en el de Intendencia y en el de Intervención Para más datos ver: Ramírez S. "Creación de la Academia de Intendencia en 1911". Suplemento Armas y Cuerpos. 15-VII2011.

13. Quevedo y Medina R. Op. Cit. pp. 435-438.

14. La ración de un soldado ingles o francés incluía: 567 gr. de carne fresca o enfriada ó 453 gr. de carne conservada, 567 gr. de pan, 85 gr. de queso, 85 gr. de azúcar, 14 gr. de sal, 226 gr. de vegetales frescos, 56 gr. de vegetales deshidratados, 17 gr. de té, 113 gr. de mermelada, 0,56 gr. de pimienta, 1,42 gr. de mostaza y10 gr. de chocolate.

15. Para más datos consultar Historia de la alimentación militar y los artículos de Miguel Krebs. http://www.historiacocina.com/especiales/articulos/militar1. htm.

16. "No es menos importante la solidaridad y el compañerismo necesario en estas misiones, que se ve incrementado con la confección y comida en conjunto, permitiendo momentos de distensión y apoyo mutuo, que con la ración individual no se daban, consiguiendo un mayor bienestar del personal desplegado y una mejora en la eficacia de la Unidad". Raciones colectivas en el Ejército de Tierra. Comandante Arias Ortega L. 23-X-2012.

17. Manual Técnico. Alimentación en el Ejército de Tierra (MT7-608). Mando de Adiestramiento y Doctrina. Dirección de Doctrina, Orgánica y Materiales. Ministerio de Defensa. Entrada en vigor 1-XI-2001.

18. Ibíd., p. A-2

19. Ibíd., pp. 1-2.

20. Normas para el empleo de los alimentos. Ibíd., pp. 3-5.

21. Ibíd., pp. 7-1 y 2 .

22. La alimentación en operaciones de fuerza de proyección, ejercicios y maniobras. Ibíd., pp. 1-5.

23. Las unidades del Ejército de Tierra tienen de dotación la cocina Arpa 2000/250 sobre remolque y la cocina Arpa MC-2 600/800 sobre contenedor.

24. Manual Técnico. Alimentación en el Ejército de Tierra. Op. Cit., p. 1-6.

25. Ibíd., p. A-8.

26. Ibíd., pp. A-8 y 9.

27. Ibíd., p. A-9.

28. Ibíd., p. A-10

29. Ibíd., p. A-12.

30. Ibíd., p. A-11.

31. La ración debe tener los aportes energéticos y calóricos reseñados por Acuerdo Normalizado de la OTAN 2937, aprobado por Orden Ministerial Comunicada Delegada de 30 de noviembre. Pliego de Prescripciones Técnicas. (PPT) Ración Individual de Combate. Ministerio de Defensa. Ejército de Tierra. Mando de Apoyo Logístico. 28-VI-2009.
32. La caja de desayuno medirá 149x105x59 cm., la de comida A 169x106x68 cm. y la de comida B 169x106x68 cm.

33. Negro el $n^{\circ} 1$, rojo el $n^{\circ} 2$, azul el $n^{\circ} 3$, verde pálido el $n^{\circ} 4$ y blanco el $n^{\circ} 5$. PPT, 28-VI-2009.

34. Ibíd.

35. Ibíd.

36. PPT de la Ración Individual de Combate para personal musulmán. Ministerio de Defensa. Ejército de Tierra. Mando de Apoyo Logístico. 28-VI-2009.

37. PPT de la Ración de pan galleta. Ministerio de Defensa. Ejército de Tierra. Mando de Apoyo Logístico. 28-VI-2009.

38. PPT de la Ración de pan de larga duración. Ministerio de Defensa. Ejército de Tierra. Mando de Apoyo Logístico. 28-VI-2009.

39. PPT del Refuerzo especial (suplemento energético RIC). Ministerio de Defensa. Ejército de Tierra. Mando de Apoyo Logístico. 28-VI-2009.

40. PPT de la Ración Individual de Emergencia. Ministerio de Defensa. Ejército de Tierra. Mando de Apoyo Logístico. 28-VI-2009.

41. PPT del Batido de Alto Contenido en Proteínas. Ministerio de Defensa. Ejército de Tierra. Mando de Apoyo Logístico. 15-VI-2010.

42. La RIL está distribuida por Teógenes Ruiz S. L. y la de refuerzo por Alonso Hipercas S. L.

43. http://intra.mdef.es/portal/intradef/Ministerio_de_Defensa/Ejercito_de_Tierra/Inicio/El_Ejercito_Informa/Actualidad?pi_s050003_2idContenido $=090$ 03a99802d72ea\&pi_s050003_2_portletAccion=com.mdef.intranet.portlets. contenidos.action.DetalleContenidoAction.

44. Informe "Modelo de alimentación en campaña y de los medios necesarios para implantarlo", redactado por el Tcol. Rafael Tinahones García, 1-IX2011.

45. Según refiere la Capitán Enfermera Alicia Moreno, las raciones eran parte de la decoración, era la mesita de noche en los refugios en Jablanica.

46. Base España. Brigada Plus Ultra. Ad Diwaniyah (Irak).INSE. Datos facilitados por la Cabo especialista Elena Gosser García.

47. Datos facilitados por el Capitán Enfermero Fernando Piñol Jané.

48. El personal militar es un Cabo $1^{\circ}$ y una Cabo especialistas en Hostelería y Alimentación (HAM), formados en la ACLOG.

49. Entrevista personal al Teniente coronel de Intendencia Juan Covas Calafell, Jefe del Servicio de Alimentación de la Academia General Militar, el 19-X2012.

50. Procedimiento: gestión de artículos de clase I, por el Centro de Gestión de la Distribución, oficinas de control y unidades consumidoras. Subdirección de Abastecimiento. Centro de Gestión de la Distribución. Septiembre 2011 